\title{
Four new genera of the Ceratonotus group (Copepoda, Harpacticoida), including the description of two new species
}

\author{
Kai Horst GEORGE \\ Senckenberg am Meer Wilhelmshaven, German Centre for Marine Biodiversity, Research DZMB, \\ Südstrand 44, 26382 Wilhelmshaven, Germany. \\ Email: kai.george@senckenberg.de \\ urn:1sid:zoobank.org:author:4399979D-C00B-4798-A524-2F51E8DAB73C
}

\begin{abstract}
In the framework of an ongoing extensive phylogenetic evaluation of the Ceratonotus group (Copepoda, Harpacticoida, Cletodidae), Poropsyllus menzelae gen. et sp. nov. from the sublittoral of south-western Cyprus (eastern Mediterranean Sea) and Paratouphapleura aaroni gen. et sp. nov. from the western Weddell Sea (Antarctica) are described. Both new species fit the autapomorphies of the $\mathrm{Ce}$ ratonotus group but cannot be assigned to any of the genera so far known. Instead, each new species presents a set of derived characters that justify their placement in new genera, Poropsyllus gen. nov. and $\mathrm{Pa}$ ratouphapleura gen. nov., respectively. Furthermore, a comparison of the species placed in Ceratonotus Sars revealed that because of exclusive morphological deviations, Ceratonotus concavus Conroy-Dalton, C. steiningeri George, C. tauroides George, and C. vareschii George should be excluded from Ceratonotus and transferred to a new monophylum, Tauroceratus gen. nov. Likewise, Polyascophorus monoceratus George, Wandeness \& Santos is characterized by several apomorphies that justify its transfer from Polyascophorus to a new taxon, Pseudopolyascophorus gen. nov. The Ceratonotus group is therefore increased to 31 species assigned to 13 genera. The systematic modifications conducted and resulting phylogenetic consequences are discussed in detail.
\end{abstract}

Keywords. Antarctica, Crustacea, Cyprus, meiofauna, systematics.

George K.H. 2021. Four new genera of the Ceratonotus group (Copepoda, Harpacticoida), including the description of two new species. European Journal of Taxonomy 774: 1-41. https://doi.org/10.5852/ejt.2021.774.1525

\section{Introduction}

Currently the Ceratonotus group sensu Conroy-Dalton (2001) comprises nine genera: Arthuricornua Conroy-Dalton, 2001, Ceratonotus Sars, 1909, Dendropsyllus Conroy-Dalton, 2003, Dimorphipodia Lee \& Huys, 2019, Dorsiceratus Drzycimski, 1967, Echinopsyllus Sars, 1909, Polyascophorus George, 1998, Pseudechinopsyllus George, 2006, and Touphapleura Conroy-Dalton, 2001 (Sars1909; Drzycimski 1967; George 1998, 2006a; Conroy-Dalton 2001; Conroy-Dalton 2003a; Lee \& Huys 2019). A first detailed systematic evaluation of the Ceratonotus group was made by Conroy-Dalton (2001), who in that context established the name, recognizing Touphapleura as the most ancestral representative. Subsequent studies focused rather on the description of new species, often resulting in the establishment of new genera (Conroy-Dalton 2001, 2003a; George 2006a, 2006b; George \& Plum 2009; Wandeness 
et al. 2009; George et al. 2013; Gómez \& Díaz 2017; Lee \& Huys 2019), but only Lee \& Huys (2019) and George (2020) provided - about two decades after Conroy-Dalton's (2001) first attempt - new insights into the systematic relationships within the Ceratonotus group itself. While Lee \& Huys (2019) focused in particular on the homologisation of the cuticular body processes, setular/spinulose tufts, and tubercles that are characteristic of the Ceratonotus group, George's (2020) phylogenetic evaluation resulted in the transfer of the taxon from the Ancorabolidae Sars, 1909, to the Cletodidae T. Scott, 1904, sensu Por (1986).

In the framework of an ongoing phylogenetic evaluation of the Ceratonotus group, a new genus, Poropsyllus gen. nov., is established to accommodate a new species from the eastern Mediterranean Sea. A second new species resembling Touphapleura in several (plesiomorphic) character states but at the same time presenting derived features is described from the high Antarctic and placed in a new taxon, Paratouphapleura gen. nov. Furthermore, four species, so far assigned to the taxon Ceratonotus, are transferred into a new genus Tauroceratus gen. nov. Finally, Polyascophorus monoceratus George et al., 2013 is excluded from that genus and placed in Pseudopolyascophorus gen. nov. The respective systematic modifications, based on 27 morphological characters and justifying the establishment of the above-named new taxa, are discussed in detail.

\section{Material and methods}

The two specimens of Poropsyllus menzelae gen. et sp. nov. described here were collected by Prof. F.D. Por in October 1968 southwest of Cyprus (eastern Mediterranean Sea, Fig. 1) (Por et al. 1972) using an Ockelmann detritus sledge (Ockelmann 1964). For the identification and description, the partly damaged individuals were embedded in glycerol, and each was placed on one slide. Because dissection would have caused further destruction of the individuals, species identification and drawings were made without dissection with a camera lucida on a Leica DMR compound microscope equipped with differential interference contrast. The material is deposited at the National Natural History Collections of the Hebrew University of Jerusalem, Israel (HUJ).

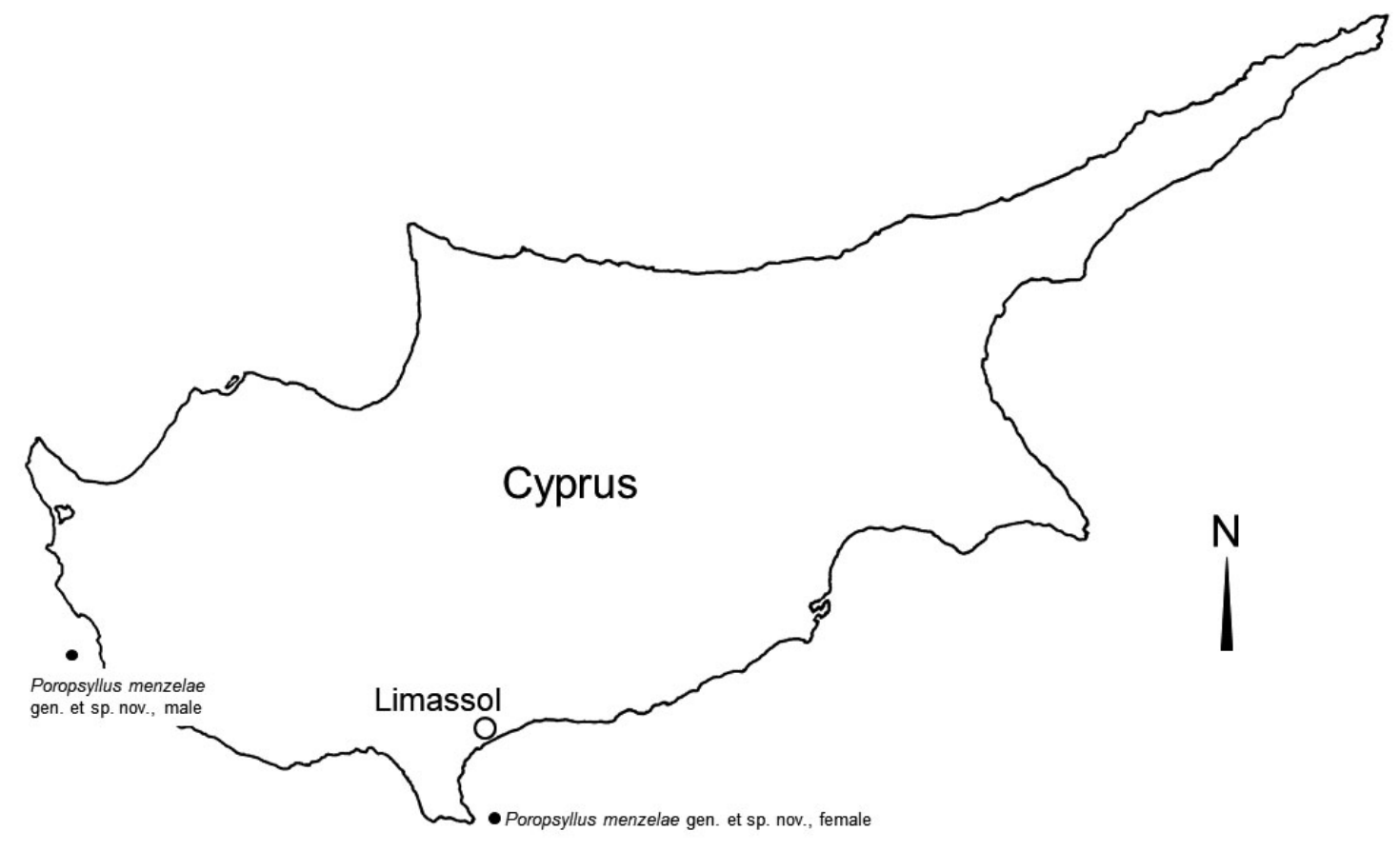

Fig. 1. Map of the island of Cyprus (eastern Mediterranean Sea) showing the locations where the two individuals of Poropsyllus menzelae gen. et sp. nov. were collected. 
The material of Paratouphapleura aaroni gen. et sp. nov. was collected during the ANDEEP II expedition ANT XIX/4 of RV Polarstern in 2002 (Fütterer et al. 2003). Sampling was done at station \#133 on the eastern continental slope off the Antarctic Peninsula (Fig. 2) with a multiple corer (MUC) (Gooday et al. 2004). It comprises three females and three males here designated as type material. The specimens showed a remarkable coverage with compact detritus and were partly damaged (antennulae broken, cephalothorax partly crushed, furcal setae missing), but a detailed species description was possible. The type material is deposited in the collection of the Senckenberg Forschungsinstitut und Naturmuseum Frankfurt/Main, Germany (SMF).

For the phylogenetic evaluation, morphological comparison was based on original species (re-) descriptions and, so far as possible, on available (type) material.

General scientific terminology follows a literal translation of Lang (1948) with additional terms from Huys \& Boxshall (1991). Phylogenetic terminology is translated from Ax (1984). The terms 'telson' and 'furca' are adopted from Schminke (1976). The terminology regarding cuticular outgrowths and ornamentation of the cephalothorax and body somites follows Lee \& Huys (2019).

\begin{tabular}{|c|c|c|}
\hline \multicolumn{3}{|c|}{ Abbreviations } \\
\hline A1 & $=$ & antennule \\
\hline $\mathrm{A} 2$ & $=$ & antenna \\
\hline $\mathrm{ACST}$ & $=$ & anterior cephalothoracic setulose tufts \\
\hline aes & $=$ & aesthetasc \\
\hline AST1-AST4 & $=$ & abdominal lateral setulose tufts \\
\hline CADP & $=$ & cephalothoracic anterodorsal processes \\
\hline CeDeTa & $=$ & $\begin{array}{l}\text { supposed monophylum composed of Ceratonotus, Dendropsyllus, and } \\
\text { Tauroceratus gen. nov. }\end{array}$ \\
\hline CLDP & $=$ & cephalothoracic laterodorsal processes \\
\hline CLVEa & $=$ & cephalothoracic anterior lateroventral extensions \\
\hline CLVEp & $=$ & cephalothoracic posterior lateroventral extensions \\
\hline CLVPa & $=$ & cephalothoracic anterior lateroventral processes \\
\hline CLVPp & $=$ & cephalothoracic posterior lateroventral processes \\
\hline cphth & $=$ & cephalothorax \\
\hline DP1-DP6 & $=$ & dorsal processes $1-6$ \\
\hline DT1-DT3 & $=$ & dorsal sensillate tubercles $1-3$ \\
\hline enp-1-enp-3 & $=$ & endopodal segments $1-3$ \\
\hline exp-1-exp-3 & $=$ & exopodal segments $1-3$ \\
\hline FH & $=$ & cephalothoracic frontal horns \\
\hline FLH & $=$ & cephalothoracic frontolateral horns \\
\hline FR & $=$ & furcal ramus/rami \\
\hline GDS & $=$ & genital double somite \\
\hline GF & $=$ & genital field \\
\hline GST & $=$ & lateral setulose tufts on female genital somite \\
\hline LT1-LT2 & $=$ & lateral sensillate tubercles $1-2$ \\
\hline $\mathrm{md}$ & $=$ & mandible \\
\hline $\mathrm{mx}$ & $=$ & maxilla \\
\hline $\mathrm{mxl}$ & $=$ & maxillula \\
\hline $\operatorname{mxp}$ & $=$ & maxilliped \\
\hline $\mathrm{P} 1-\mathrm{P} 6$ & $=$ & swimming legs $1-6$ \\
\hline PCST & $=$ & posterior cephalothoracic setulose tufts \\
\hline RST & $=$ & rostral setulose tuft \\
\hline TST1-TST4 & $=$ & lateral thoracic setulose tufts \\
\hline
\end{tabular}




\title{
Results
}

\author{
Phylum Arthropoda von Siebold, 1848 \\ Subphylum Crustacea Brünnich, 1772 \\ Superclass Multicrustacea Regier et al., 2010 \\ Subclass Copepoda Milne-Edwards, 1840 \\ Order Harpacticoida Sars, 1903 \\ Family Cletodidae T. Scott, 1905 \\ Subfamily Cletodinae T. Scott, 1905 \\ Ceratonotus group sensu Conroy-Dalton (2001)
}

\section{Included genera}

Arthuricornua Conroy-Dalton, 2001 (monotypic); Ceratonotus Sars, 1909 (four species); Dendropsyllus Conroy-Dalton, 2003 (five species); Dimorphipodia Lee \& Huys, 2019 (monotypic); Dorsiceratus Drzycimski, 1967 (five species); Echinopsyllus Sars, 1909 (four species); Paratouphapleura gen. nov. (monotypic); Polyascophorus George, 1998 (two species); Poropsyllus gen. nov. (monotypic); Pseudechinopsyllus George, 2006 (monotypic); Pseudopolyascophorus gen. nov. (monotypic); Tauroceratus gen. nov. (four species); Touphapleura Conroy-Dalton, 2001 (monotypic).

Genus Poropsyllus gen. nov. urn:1sid:zoobank.org:act:FF3B0077-C40A-464C-9D52-B0F43FA82497

\section{Etymology}

The generic name is given in respectful remembrance of the collector of the species, Prof. Dr Francis Dov Por (Israel) and is a compound of the collector's name and the Greek $\psi v 0 \lambda \lambda \mathrm{s}$ [psillos] ('flea'), a term often used in the naming of taxa of the Ceratonotus group (e.g., Dendropsyllus, Echinopsyllus, Pseudechinopsyllus). Gender: masculine.

\section{Type and only species}

Poropsyllus menzelae gen. et sp. nov.

\section{Diagnosis}

Member of Cletodidae T. Scott, 1905, Cletodinae T. Scott, 1905 and Ceratonotus group sensu Conroy-Dalton (2001). Body elongate, cylindrical, podoplean boundary between pro- and urosoma inconspicuous. Sexual dimorphism in A1, P3, P5, and P6; female with GDS due to fusion of last (P6bearing) thoracic and first abdominal (genital) somites. Cphth about $1 / 4$ of total body length, with some sensilla and long tube pores laterally and dorsally; moreover, with small, sensilla-bearing frontolateral horns (FLH), ventrally directed cephalothoracic anterior lateroventral processes (CLVPa), and bifurcate cephalothoracic posterior lateroventral processes (CLVPp). Cephalic front produced into a massive diverging peak. P2-P4-bearing pedigerous somites with dorsal cuticular processes. Rostrum absent, original central position indicated by small paired membranous projections accompanied by a pair of sensilla and 1 tube pore. Body somites except last thoracic somite (= anterior half of female GDS) and telson laterally with 1 long tube pore. Thoracic body somites dorsally also with 1 long tube pore. Telson broader than long, trapezoid in dorsal view, anal operculum flanked by 2 sensilla, posterior margin with row of fine spinules. FR long and slender, diverging, with 7 setae. Female A1 slender, 4-segmented, male A1 sexually dimorphic, number of segments unknown. A2 without exopod, allobasis with 2 abexopodal setae; endopod 1-segmented, with 2 spines and 1 slender additional seta; apically with 5 setae, 3 of which geniculate. Intercoxal sclerites of $\mathrm{P} 1-\mathrm{P} 4$ slender, bow-like; P1 with transversely elongated basis and 2-segmented exopod, endopod absent, represented by 1 long bare seta; bases of P2-P4 showing extreme transverse elongation, without endopods, except male P3, which bears a 3-segmented endopod 
with an apophysis on enp-2. P5 also considerably elongated, reaching anterior margin of telson; in the female with exopod fused to baseoendopod, in male exopod distinct.

Poropsyllus menzelae gen et sp. nov.

urn:1sid:zoobank.org:act:D3681697-E1C8-40A4-8CC4-7DEB1705903E

Figs 1-7; Table 1

\section{Etymology}

The epitheton menzelae is given in friendly dedication to Dr Lena Menzel (Bremerhaven, Germany), who obtained the material from Prof. Por and placed it at the author's disposal for further study.

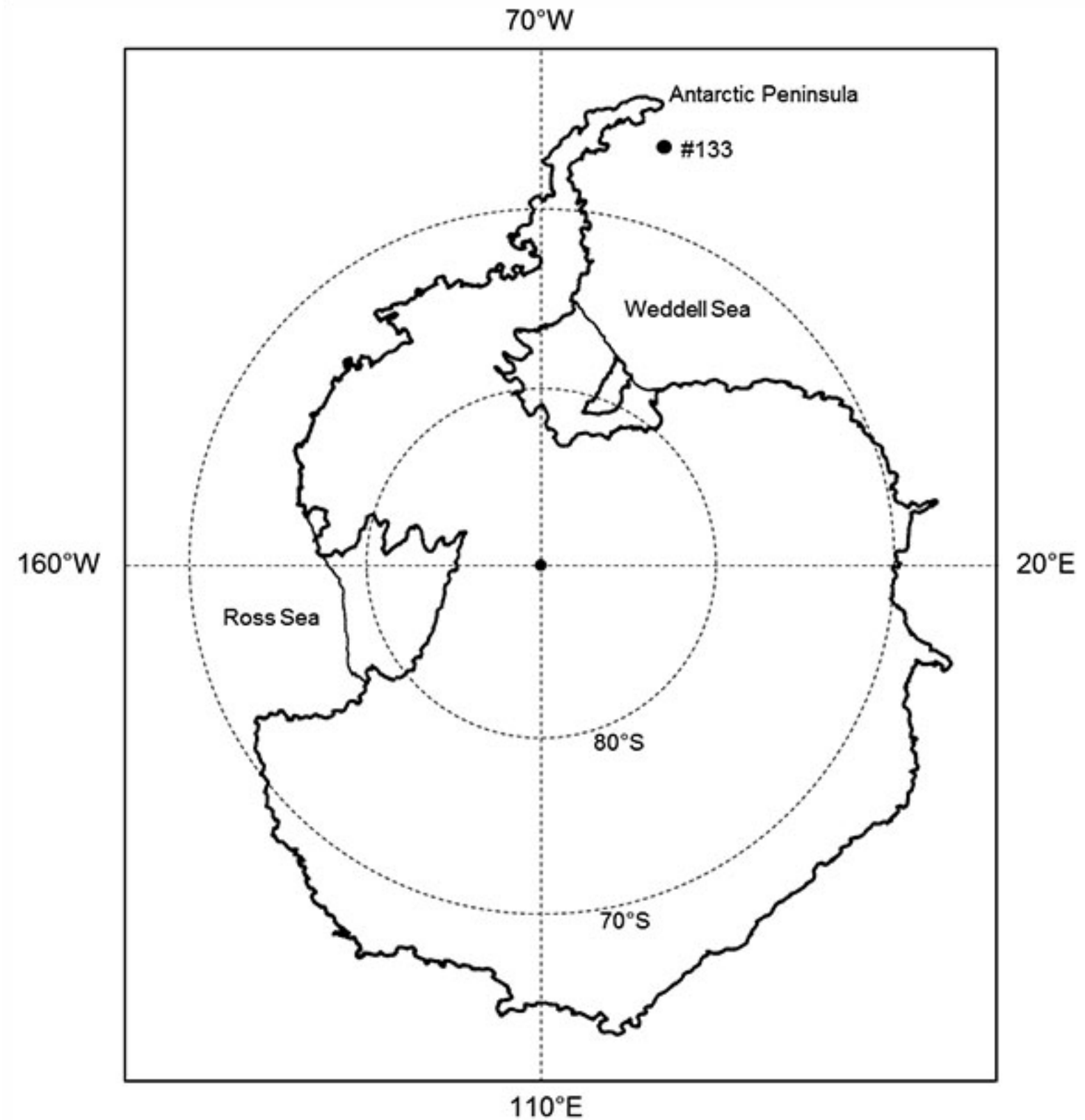

Fig. 2. Map of Antarctica showing sampling station \#133, the type locality of Paratouphapleura aaroni gen. et sp. nov., on the eastern continental slope off the Antarctic Peninsula. 


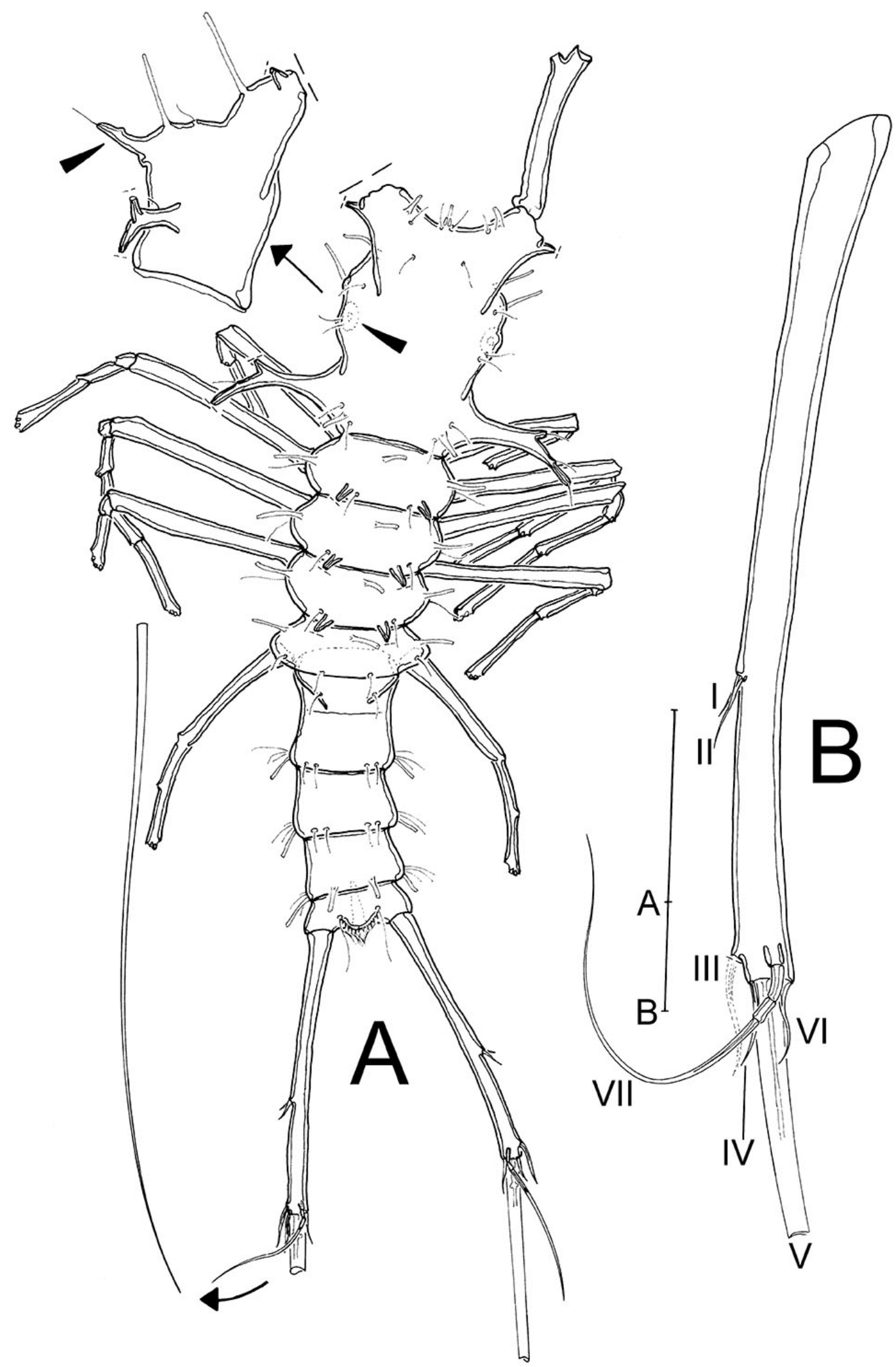

Fig. 3. Poropsyllus menzelae gen. et sp. nov., female holotype (HUJ INVCRUCOP808). A. Habitus, dorsal view; on the upper left: cphth in lateral view; arrowheads point to the CLVPa. B. Left FR, dorsal view. Scales bars: $A=100 \mu \mathrm{m} ; \mathrm{B}=50 \mu \mathrm{m}$. 


\section{Type material}

\section{Holotype}

CYPRUS - $q$; Akrotiri Bay (locus typicus), E of Cape Gata (S Cyprus); geographic transect: $34^{\circ} 33^{\prime} 54^{\prime \prime} \mathrm{N} / 33^{\circ} 02^{\prime} 45^{\prime \prime} \mathrm{E}-34^{\circ} 34^{\prime} 20^{\prime \prime} \mathrm{N} / 33^{\circ} 04^{\prime} 06^{\prime \prime} \mathrm{E}$; depth 115 fathoms (=210.5 m); 26 Oct. 1968; F.D. Por leg.; Ockelmann detritus sledge (Por et al. 1972); HUJ INVCRUCOP808, on 1 slide.

\section{Paratype (allotype)}

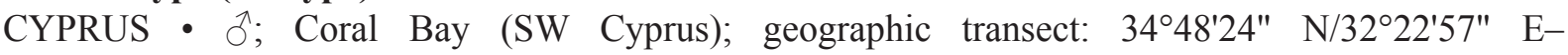
$34^{\circ} 48^{\prime} 06^{\prime \prime} \mathrm{N} / 32^{\circ} 21^{\prime 2} 24^{\prime \prime}$ E; depth 100 fathoms (= 183.0 m); 31 Oct. 1968 F.D. Por leg.; Ockelmann detritus sledge (Por et al. 1972); HUJ INVCRUCOP809, on 1 slide.

Both specimens show several instances of damage, mainly loss of setae, segments of appendages, and both antennular segments and cuticular processes (male allotype). Dissection, which would have caused further destruction of the individuals, was not conducted, but all parts except the maxillula were drawn and described.

\section{Description}

\section{Female}

HaBitus (Fig. 3A). Elongate, cylindrical (body length including FR $550 \mu \mathrm{m}$ ), podoplean boundary between pro- and urosoma inconspicuous. Cphth about $1 / 4$ of total body length, with some sensilla and long tube pores laterally and dorsally; moreover, with small frontolateral horns (FLH), ventrally directed cephalothoracic anterior lateroventral processes (CLVPa) (arrowheads in Fig. 3A), and bifurcate cephalothoracic posterior lateroventral processes (CLVPp). Cephalic front produced into a massive diverging peak, from which the $\mathrm{A} 1$ arises. Rostrum (Figs 3A, 4A) absent, original central position indicated by small paired membranous projections accompanied by a pair of sensilla and 1 tube pore. P2-P4-bearing pedigerous somites with small dorsal cuticular processes (DP1-DP3); each process carrying a sensillum at its tip (most of them broken in Fig. 3A). Body somites except last thoracic somite (= anterior half of female GDS) and telson laterally with 1 long tube pore. Thoracic body somites with additional dorsal long tube pore. First abdominal somite fused with last thoracic body somite to form a GDS. Thoracic part of GDS dorsally with pair of diagonal cuticular ridges; abdominal part of GDS and abdominal somites except telson with abdominal lateral setulose tufts (AST1-AST3). Telson broader than long, trapezoidal in dorsal view, anal operculum flanked by 2 sensilla, posterior margin with row of fine spinules.

FR (Fig. 3A-B). Diverging, rami slender, about 11 times as long as broad and longer than abdomen and GDS together, bearing 7 bare setae (Fig. 3B). Setae I and II inserting laterally, standing close together, I minute, II twice as long as I; III inserting subapically on outer margin; setae IV and V located apically, IV slightly smaller than III, and V as long as fifth pedigerous somite, abdomen, and FR combined (Fig. 3A); VI as long as IV, inserting apically on inner margin; VII tri-articulate, arising dorsally from small knob.

A1 (Fig. 4B). 4-segmented, long and slender. First segment longest, second to fourth segments of almost the same size. First 3 segments with long spinules (several spinules broken in Fig. 4B). Several setae broken in Fig. 4B; first segment distally with 1 seta (broken); second segment with 7 setae (6 broken, 1 biplumose); third segment with at least 6 setae (all but 1 bare seta broken); pedestal for acrothek discernible close to apical margin (elements broken); fourth segment with 11 bare setae (1 apical seta broken), two of which fused with 1 small aes.

Armature formula: I-1; II-7; III-6(7?) + aes, IV-11 + aes. 


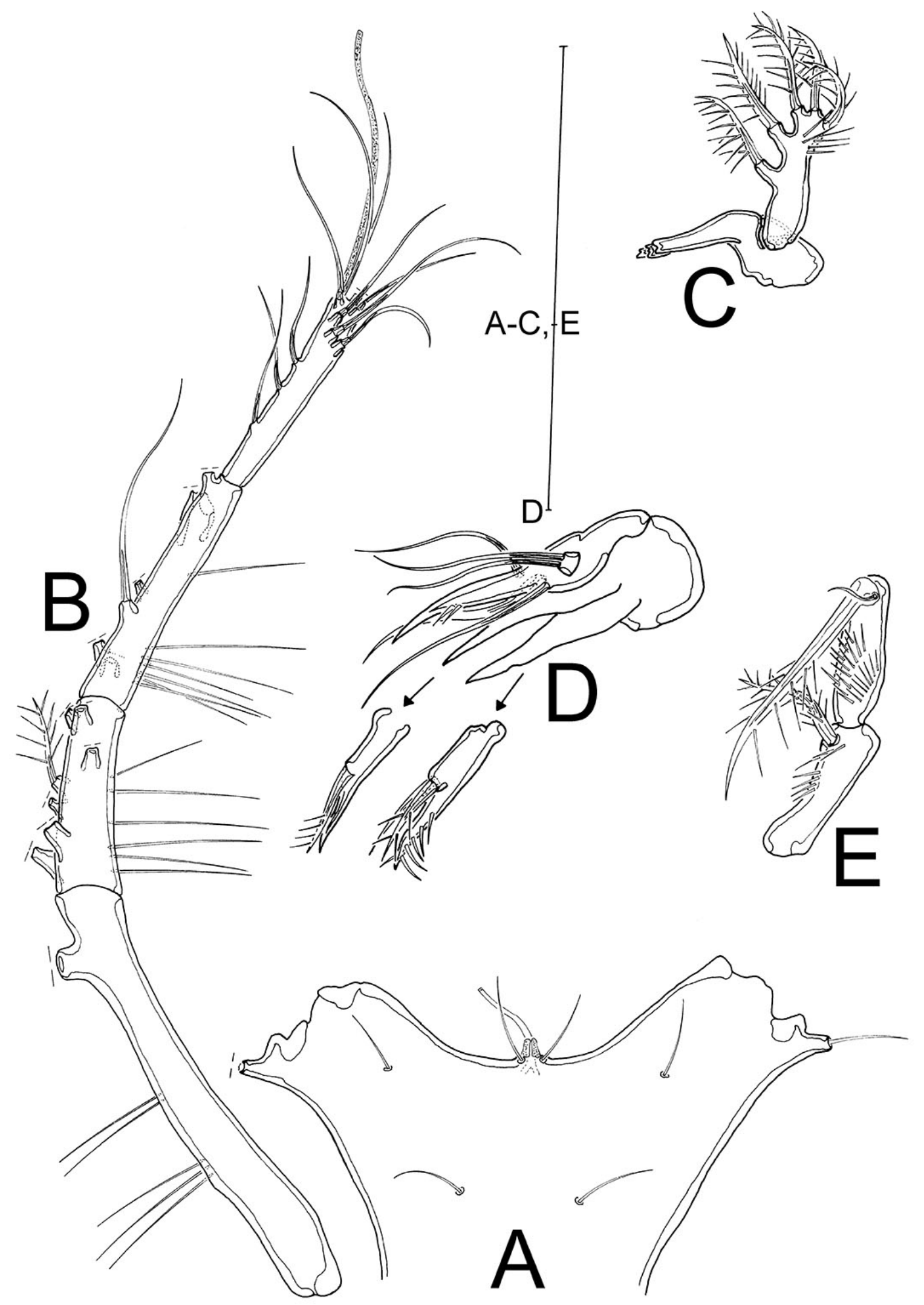

Fig. 4. Poropsyllus menzelae gen. et sp. nov., female holotype (HUJ INVCRUCOP808). A. Cephalothoracic peak. B. A1. C. Md. D. Mx. E. Mxp. Scales: $50 \mu \mathrm{m}$. 


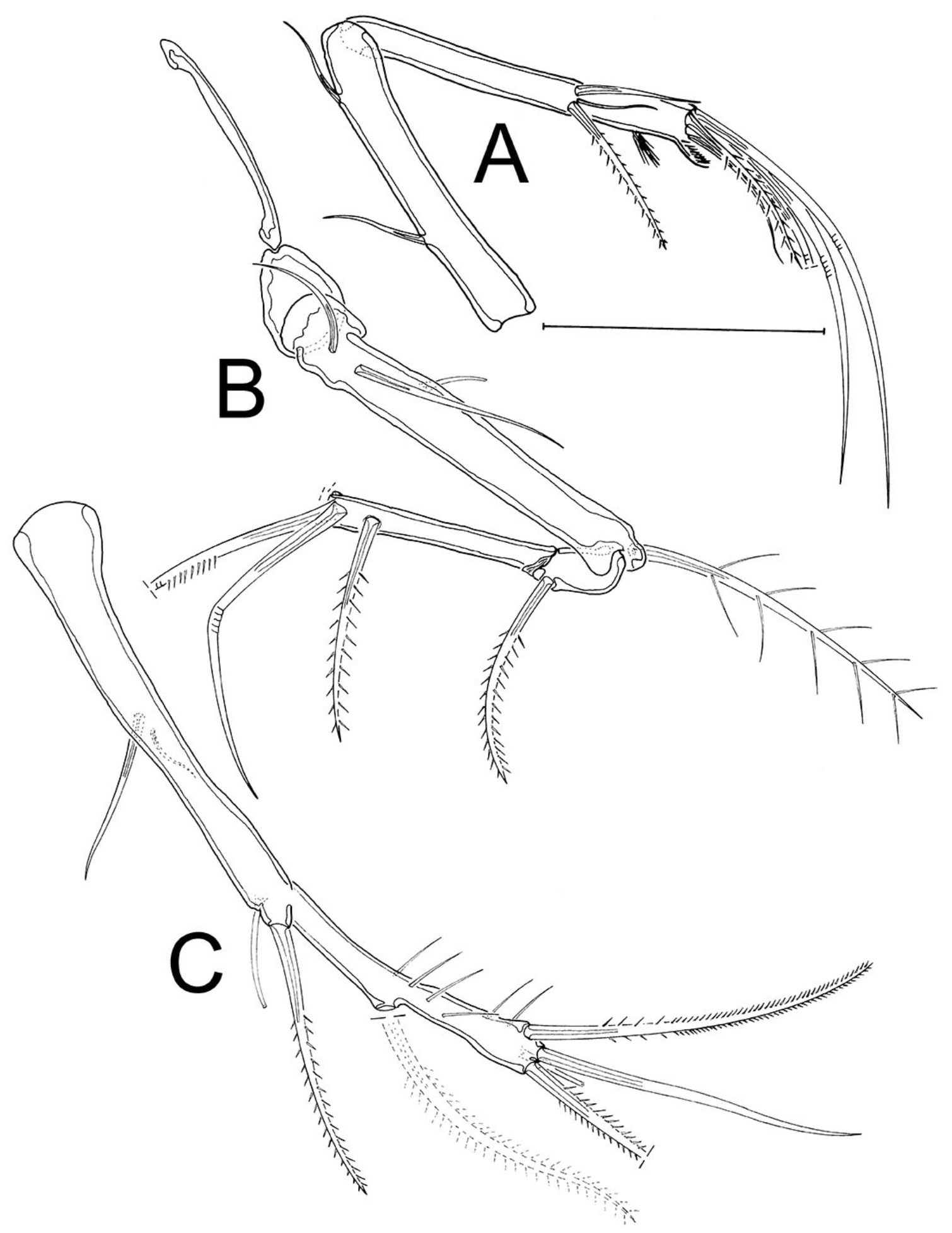

Fig. 5. Poropsyllus menzelae gen. et sp. nov. A. Male allotype (HUJ INVCRUCOP809), A2. B. Female holotype (HUJ INVCRUCOP808), P1. C. Female holotype (HUJ INVCRUCOP808), P5. Scale bar: $50 \mu \mathrm{m}$. 


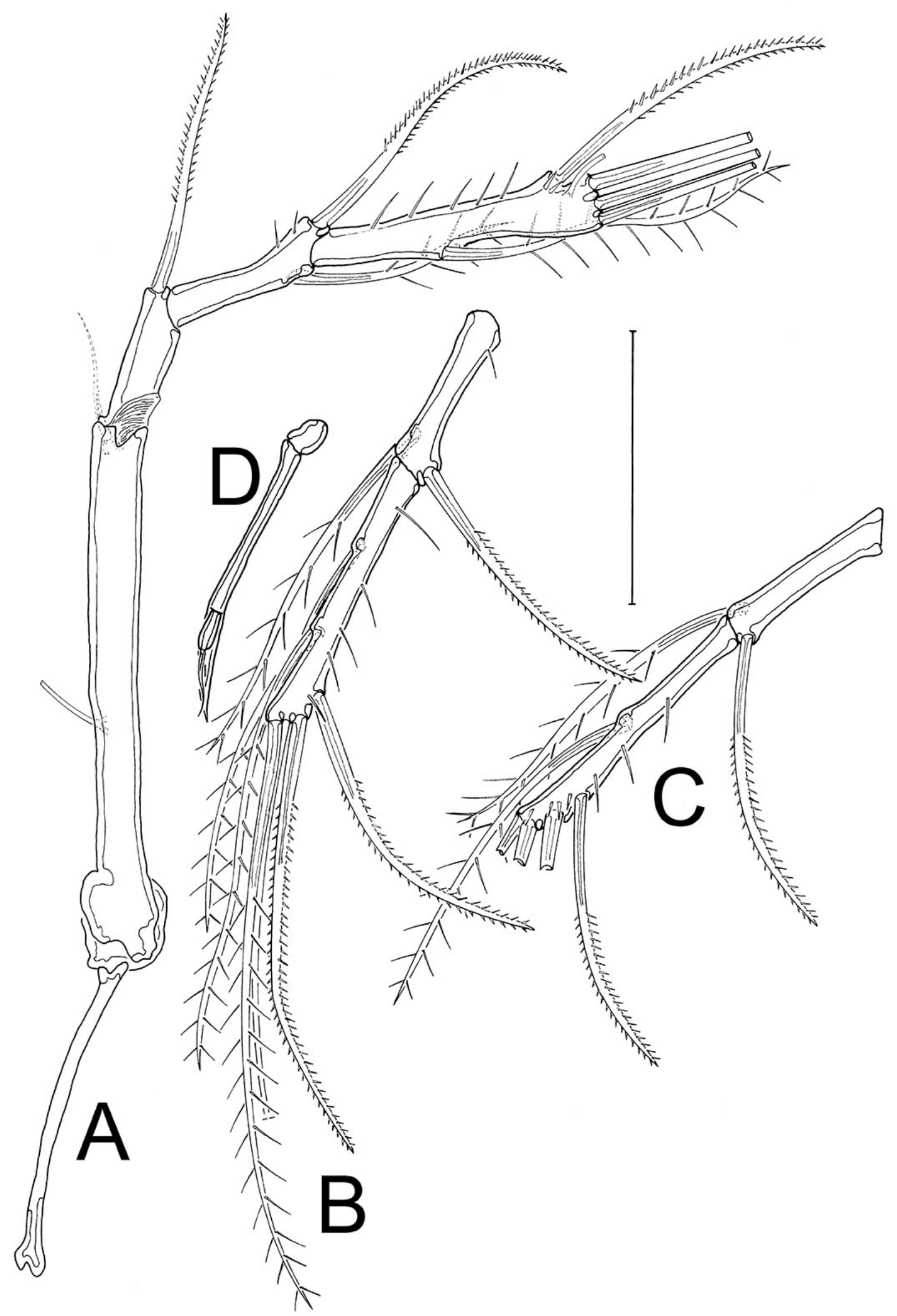

Fig. 6. Poropsyllus menzelae gen. et sp. nov. A-C. Female holotype (HUJ INVCRUCOP808). A. P2. B. P3 exp-2 and exp-3. C. P4 exp-2 and exp-3. D. Male allotype (HUJ INVCRUCOP809), P3 endopod. Scale bar: $50 \mu \mathrm{m}$. 
Table 1. Poropsyllus menzelae gen. et sp. nov., setation of swimming legs P2-P4; Roman numerals indicate outer, Arabic numerals inner elements.

\begin{tabular}{lll}
\hline Leg & Exopod & Endopod \\
\hline P2 & I-0; I-I; II-2-1 & - \\
P3 male & I- $0 ;$ I-1; II-2-2 & $0 ; 0$ (apophysis); 0-1-0 \\
P3 female & I-0; I-1; II-2-2 & - \\
P4 female & I-0; I-I; II-2-1 & - \\
\hline
\end{tabular}

A2. See description of allotype.

MD (Fig. 4C). Gnathobase small in comparison with palp, apically with 3 multicuspidate teeth; palp unilobed, subapically with some fine, long spinules, and with 2 lateral (basal) and 3 apical (endopodal) setae, all biplumose.

MxL. Because dissection, which would have caused destruction of the individuals, was not conducted, no in situ description could be made, and the mxl was not drawn.

Mx (Fig. 4D). Syncoxa and allobasis separate, syncoxa with 2 endites. Proximal endite with 1 strong unipinnate spine fused to the segment, and with 1 bare and 1 biplumose seta. Distal endite with 1 strong bare spine fused to the segment, and with 1 unipinnate seta. Allobasis with 1 claw-like element fused to the segment; additionally with 1 strong and 2 slender bare setae. Endopod distinct, small, 1-segmented, with 2 bare setae.

Mxp (Fig. 4E). Prehensile, syncoxa with few long spinules and 1 strong multipinnate seta. Basis with 3 rows of long spinules. Endopod produced into long biplumose claw, basally accompanied by 1 tiny seta.

P1-P4 (Figs 5B, 6A-C). With slender, bow-like intercoxal sclerites (Figs 5B, 6A); bases extraordinarily elongated transversely (Figs 3A, 5B, 6A), without any spinulose ornamentation, except the presence of 1 tube pore at mid-length on the anterior margin (Figs 5B, 6A). P1 (Fig. 5B) basis with 1 inner bare and 1 outer biplumose seta; with tube pore on anterior margin; endopod represented by 1 bare seta; exopod 2-segmented, exp-2 about 3 times as long as exp-1; exp-1 with 1 outer bipinnate seta; exp-2 with 1 outer bipinnate seta; apically with 4 geniculate setae (2 broken in Fig. 5B), one of which unipinnate. P2-P4 (Fig. 6A-C) without endopods; bases with 1 short bare outer seta (Fig. 6A) and with tube pore on anterior margin; exopods 3-segmented, segments with few or without spinules as depicted; exp-1 with outer bipinnate seta (Fig. 6A); exp-2 with 1 outer and 1 inner seta; exp-3 with 2 outer bipinnate setae, the posterior one shifted to an apical (P2, P3; Fig. 6A-B) or subapical position (P4; Fig. 6C); exp3 additionally with 2 apical setae. P2 exp-3 (Fig. 6A) in addition subapically with long tube pore. P2 and P4 exp-3 with 1, P3 exp-3 with 2 inner setae. Inner setae and innermost apical seta biplumose, but outermost apical seta bare. Setation of P2-P4 as in Table 1.

P5 (Fig. 5C). Baseoendopod and exopod fused. Baseoendopod with outer bipinnate seta arising from minute setophore and accompanied by 1 long tube pore. Endopodal lobe completely reduced, represented 


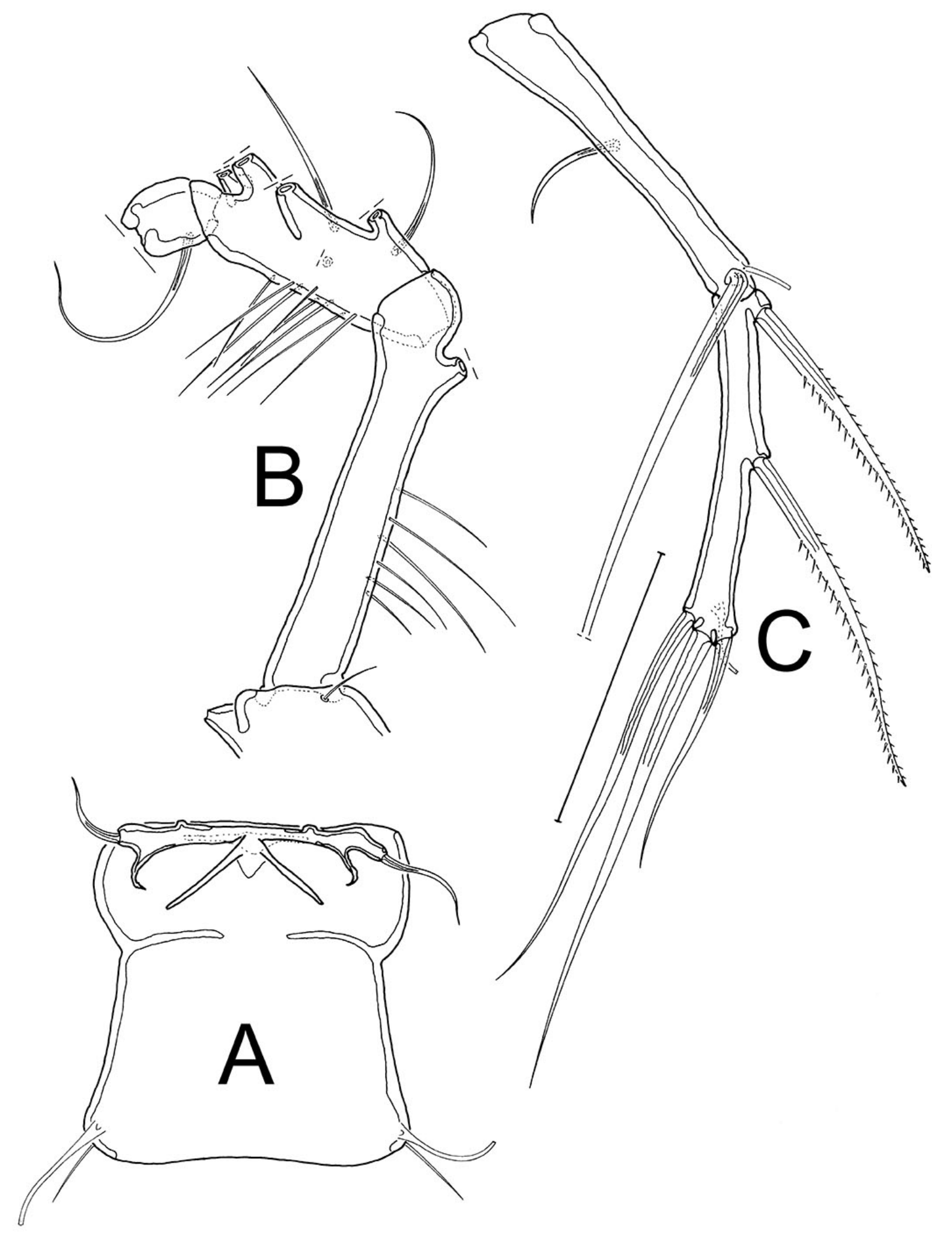

Fig. 7. Poropsyllus menzelae gen. et sp. nov. A. Female holotype (HUJ INVCRUCOP808), genital double somite with genital field and P6. B. Male allotype (HUJ INVCRUCOP809), A1, showing the first 3 segments. C. Male allotype, P5. Scale bar: $50 \mu \mathrm{m}$. 
by 1 long and 1 small bare seta. Exopodal lobe with 1 bipinnate outer seta and 3 apical setae, two of which bipinnate, the remaining one bare; subapically with long tube pore.

GF (Fig. 7A). With fused gonopores covered by slender genital operculum derived from the medially fused P6, whose minute lobes each end in a bare seta.

\section{Male}

The male resembles the female in most characters. Sexual dimorphism is expressed in a slightly smaller body size ( $480 \mu \mathrm{m}$ incl. FR), in the A1, the P3 endopod, the P5, and the absence of a P6.

A1 (Fig. 7B). Damaged, but sexual dimorphism still discernible. First segment as in female; second segment half as long as first, with 7 setae and long spinules on anterior margin; third segment about $1 / 3$ the length of previous segment, with 1 bare seta. Following segments broken, not illustrated.

A2 (Fig. 5A). Without exp. Allobasis with 2 abexopodal bare setae. Endopod laterally on distal half with 2 well-developed setae, one of which bipinnate, and with 1 small bare seta; additionally, with frill-like row of long fine spinules. Apically with 3 long geniculate setae (one broken); moreover with 1 bipinnate and 1 bare slender seta. Subapically with spinulose frill.

P3 ENDOPOD (Fig. 6D). 3-segmented, first segment small and unarmed, second segment about 6 times as long as first, ending in an acute apophysis; third segment slightly longer than first, apically with 1 small bare seta.

P5 (Fig. 7C). With exopod separated from baseoendopod, carrying 2 outer bipinnate and 3 bare apical setae; subapically with tube pore. Outer baseoendopodal seta bare, accompanied by small tube pore; endopodal lobe represented by 1 bare seta.

Genus Paratouphapleura gen. nov. urn:1sid:zoobank.org:act:883121EC-5626-40EA-BC42-CC2A7FE7B166

\section{Type and only species}

Pa. aaroni sp. nov.

\section{Etymology}

The generic name 'Paratouphapleura' is a combination of the Greek $\pi \alpha \rho \alpha$ [pará], meaning 'besides', 'beyond', and the genus name Touphapleura, pointing to the general morphological resemblance of Touphapleura and Paratouphapleura gen. nov. Gender: feminine.

\section{Diagnosis}

Membor of Cletodidae T. Scott, 1904, Cletodinae T. Scott, 1904, and the Ceratonotus group sensu Conroy-Dalton (2001). Body more or less cylindrical, tapering slightly posteriorly, without clear demarcation between pro- and urosoma. In female fusion of last thoracic (P6-bearing) and first abdominal (= genital) somite to form GDS. Cephalothorax with weakly developed cephalothoracic anterior lateroventral processes (CLVPa); cephalothoracic posterior lateroventral processes (CLVPp) well-developed, jet-wing-like, with 1 sensillum each on the anterior margin and the tip; cephalothoracic anterodorsal processes (CADP) and cephalothoracic laterodorsal processes (CLDPp) not developed; anterior cephalothoracic setulose tufts (ACST) present, posterior cephalothoracic setulose tufts (PCST) absent. Rostrum small, broader than long, fused to cephalothorax; with paired sensilla, 1 tube pore, paired membranous projections, and rostral setulose tuft (RST). Pedigerous somites dorsally with long tube pore, those bearing P2-P4 additionally with pairs of small and unarmed dorsal cuticular processes 
(DP1-DP3), each carrying a sensillum at its tip, and laterally with setulose tufts (TST1-TST3); P6-bearing somite laterally with setulose tufts (GST). Urosomal somites laterally with tube pores accompanied by abdominal lateral spinulose tufts (AST1-AST3); first abdominal somite (= posterior part of female GDS) and following 2 abdominal somites with dorsal row of spinules on posterior margin, the former and the second somite additionally with pair of tube pores dorsally. Telson half as long as penultimate somite, with spinulose anal operculum flanked by 2 sensilla and spinulose tufts (AST4) running lateroventrally at the bases of the furcal rami. The latter about three times as long as broad, with 7 setae (I-VII). Antennule 4-segmented in the female, 7-segmented and subchirocer in the male; first segment elongated and equipped with long spinules along anterior margin. Antenna with allobasis and 1-segmented endopod, without exopod; allobasis with 2 abexopodal setae; endopod with 2 spines, apically with 5 setae, 4 of which geniculate. Swimming legs with bow-like intercoxal sclerites, small coxae, and transversely elongated bases; P1 with 2-segmented lobes, non-prehensile; basis with inner and outer seta; exp-1 with 1 outer bipinnate spine, exp-2 with all elements located apically: 1 bipinnate outer spine and 4 bare or unipinnate geniculated setae. P2-P4 bases carrying 1 outer seta, with 3 -segmented exopods; P2, P4, and female P3 with 2-segmented endopods, male P3 endopod 3-segmented, enp-2 with apophysis on inner apical edge. P5 with endopodal lobe reduced to a minute pedestal with 1 seta. Female GDS with P6 strongly reduced, not forming a genital operculum.

Paratouphapleura aaroni gen. et sp. nov.

urn:1sid:zoobank.org:act:6F7C1F0C-7A6F-473A-B5B4-78859FE44D59

Figs 8-14; Table 2

\section{Etymology}

The epitheton aaroni is given in fond dedication to my brother, Mr Aaron Martin George (Münster/ Selters, Germany).

\section{Type material}

3 우, $3 \hat{\jmath} \widehat{\jmath}$, collected during research cruise ANT-XIX/4 (ANDEEP II) of RV POLARSTERN in 2002.

\section{Holotype}

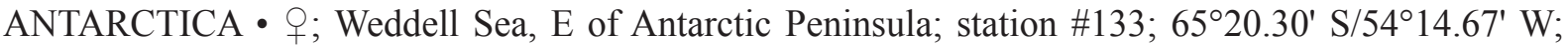
depth 1109.6 m (locus typicus); multiple corer; SMF 37270/1, on 1 slide.

\section{Paratypes}

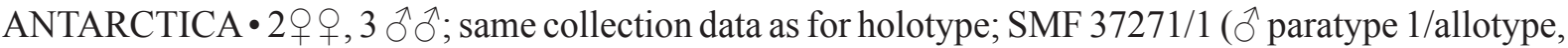
on 1 slide), SMF 37272/1 (q paratype 2, on 1 slide), SMF 37273/1-9 (q paratype 3, on 9 slides), SMF 37274/1-8 ( $§$ paratype 4 , on 8 slides), SMF 37275/1 (ð paratype 5, on 1 slide).

\section{Description}

\section{Female}

HaBitus (Fig. 8A). Elongate, cylindrical; body length including FR: $493 \mu \mathrm{m}$ (holotype), $562 \mu \mathrm{m}$ (paratype 2), $515 \mu \mathrm{m}$ (paratype 3). Podoplean boundary between pro- and urosoma inconspicuous. Cphth about $1 / 3$ of total body length, with some sensilla and long tube pores laterally and dorsally, and with anterior cephalothoracic setulose tufts (ACST). Cephalic front produced into a moderate peak, from which the A1 arises. Without frontolateral horns (FLH), but cephalothoracic anterior lateroventral processes (CLVPa) weakly developed, ending in long tube pore; sensilla not discernible. Cphth additionally with 3 pairs of tube pores, two of which located dorsally, the third laterally. Cephalothoracic posterior lateroventral processes (CLVPp) (Fig. 9B) long and jet-wing-like, with 1 sensillum halfway on anterior margin and 1 sensillum on its tip. Rostrum (Fig. 9A) small, broader than long, fused to cephalothorax; with pair of sensilla, 1 tube pore, paired membranous projections, and rostral setulose tuft (RST). P2-P4-bearing 


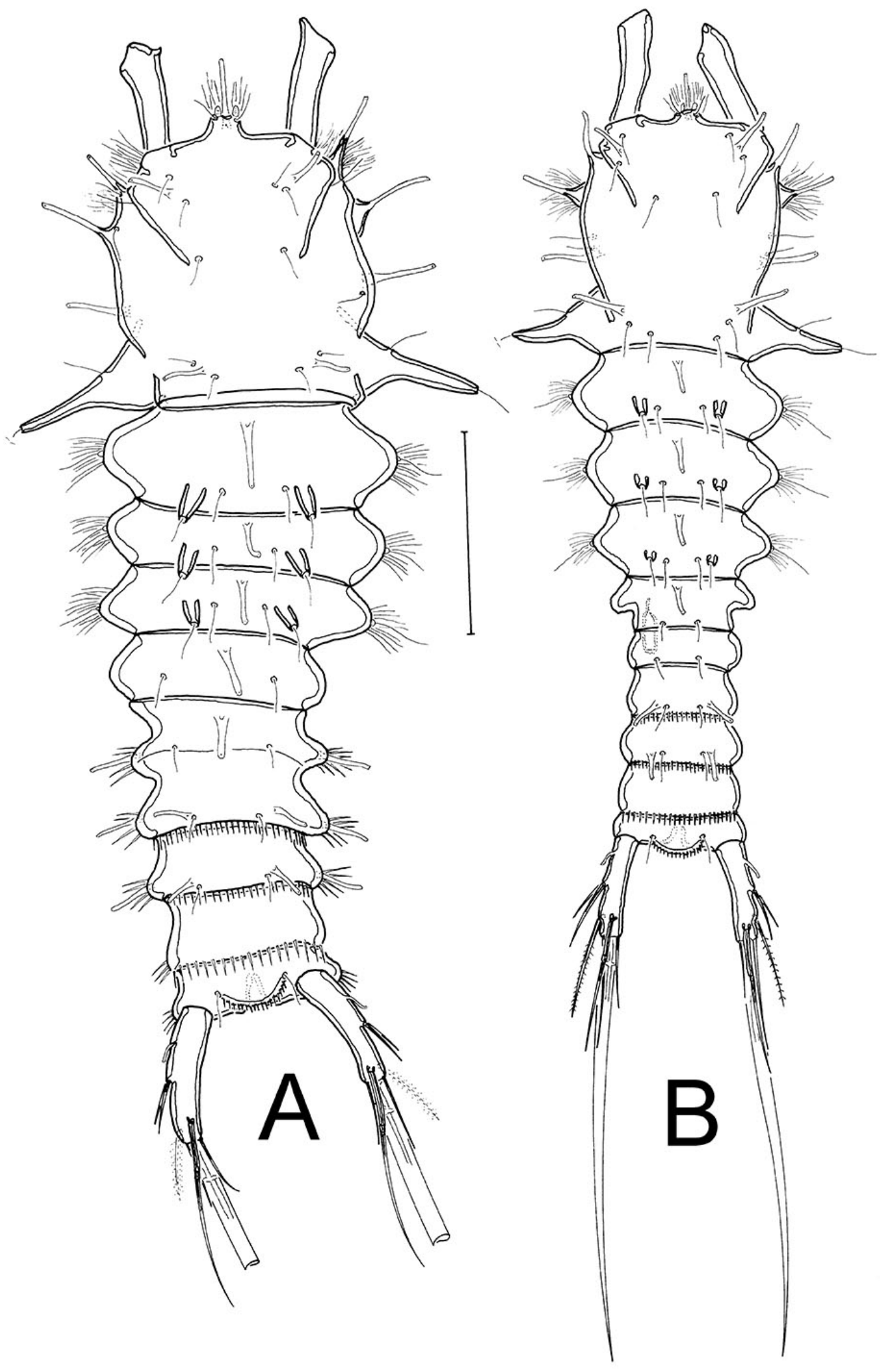

Fig. 8. Paratouphapleura aaroni gen. et sp. nov. A. Female holotype (SMF 37270/1), habitus, dorsal view. B. Male allotype (SMF 37271/1), habitus, dorsal view. Scale bar: $100 \mu \mathrm{m}$. 


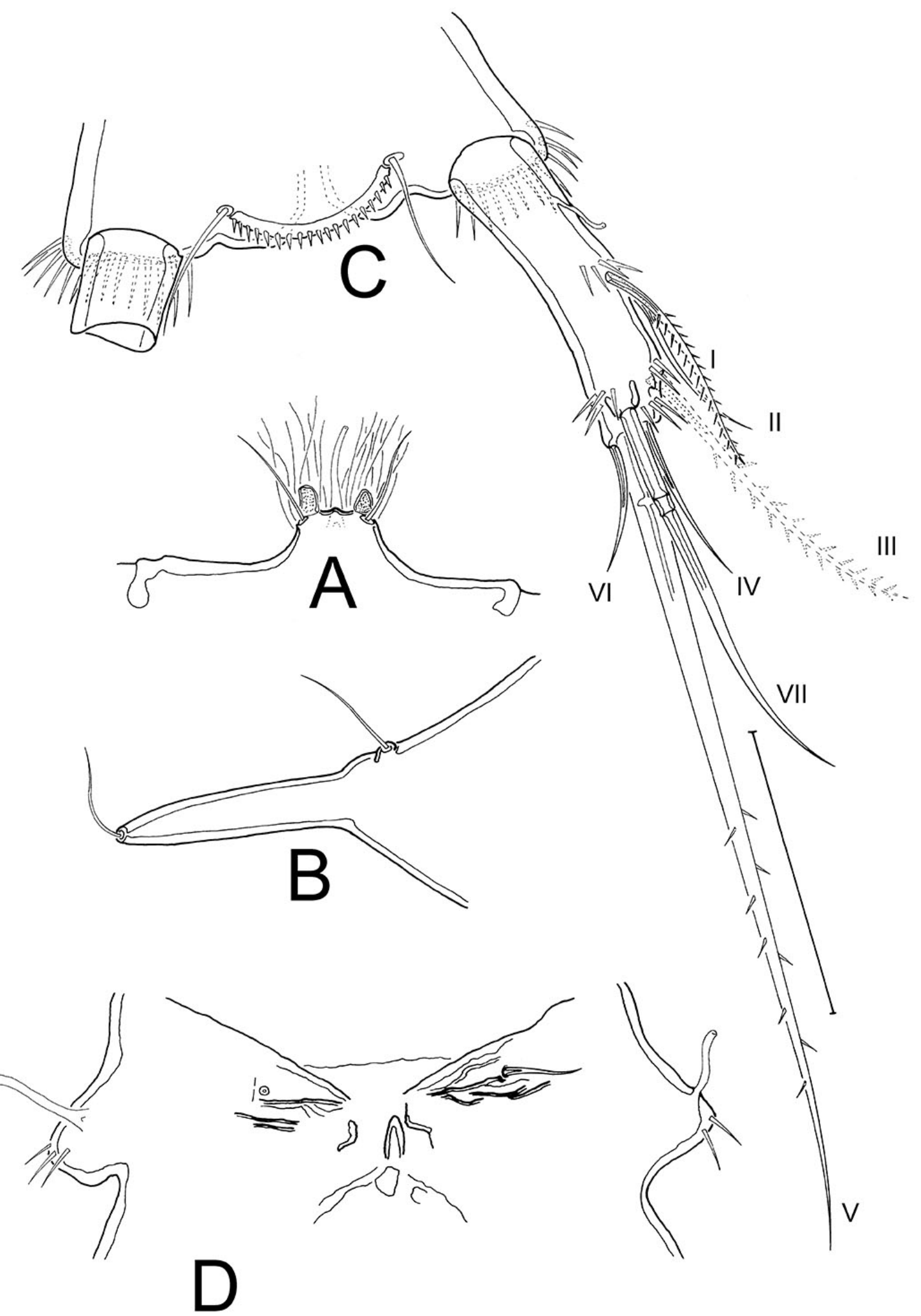

Fig. 9. Paratouphapleura aaroni gen. et sp. nov. A-C. Female holotype (SMF 37270/1). A. Rostrum, dorsal view. B. Left cephalothoracic posterior lateroventral process (CLVPp), dorsal view. C. Telson and right FR, dorsal view. D. Female paratype 3 (SMF 37273), genital field with P6. Scale bar: $50 \mu \mathrm{m}$. 


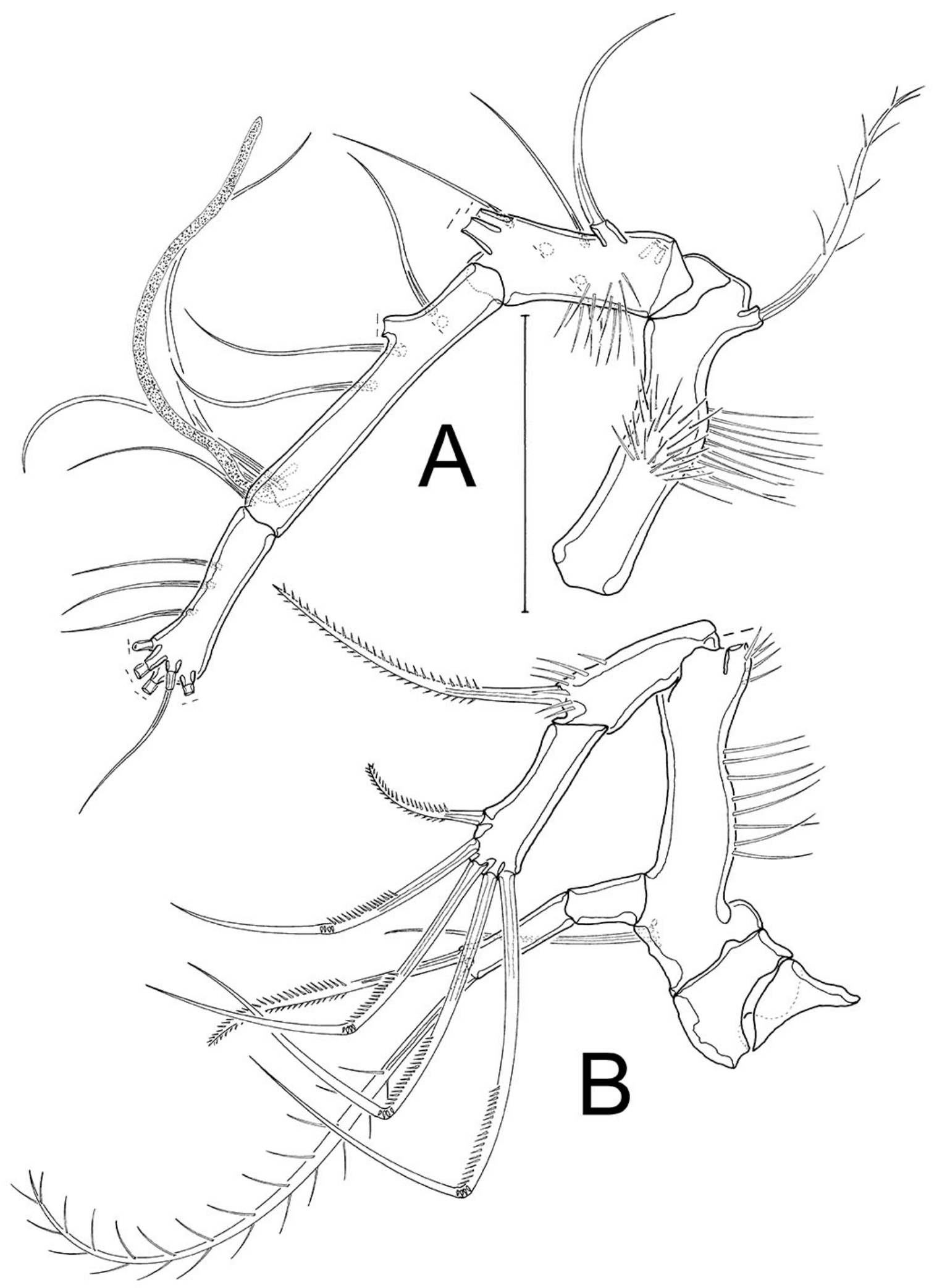

Fig. 10. Paratouphapleura aaroni gen. et sp. nov. A. Female holotype (SMF 37270/1), A1. B. Female paratype 3 (SMF 37273), P1. Scale bar: $50 \mu \mathrm{m}$. 

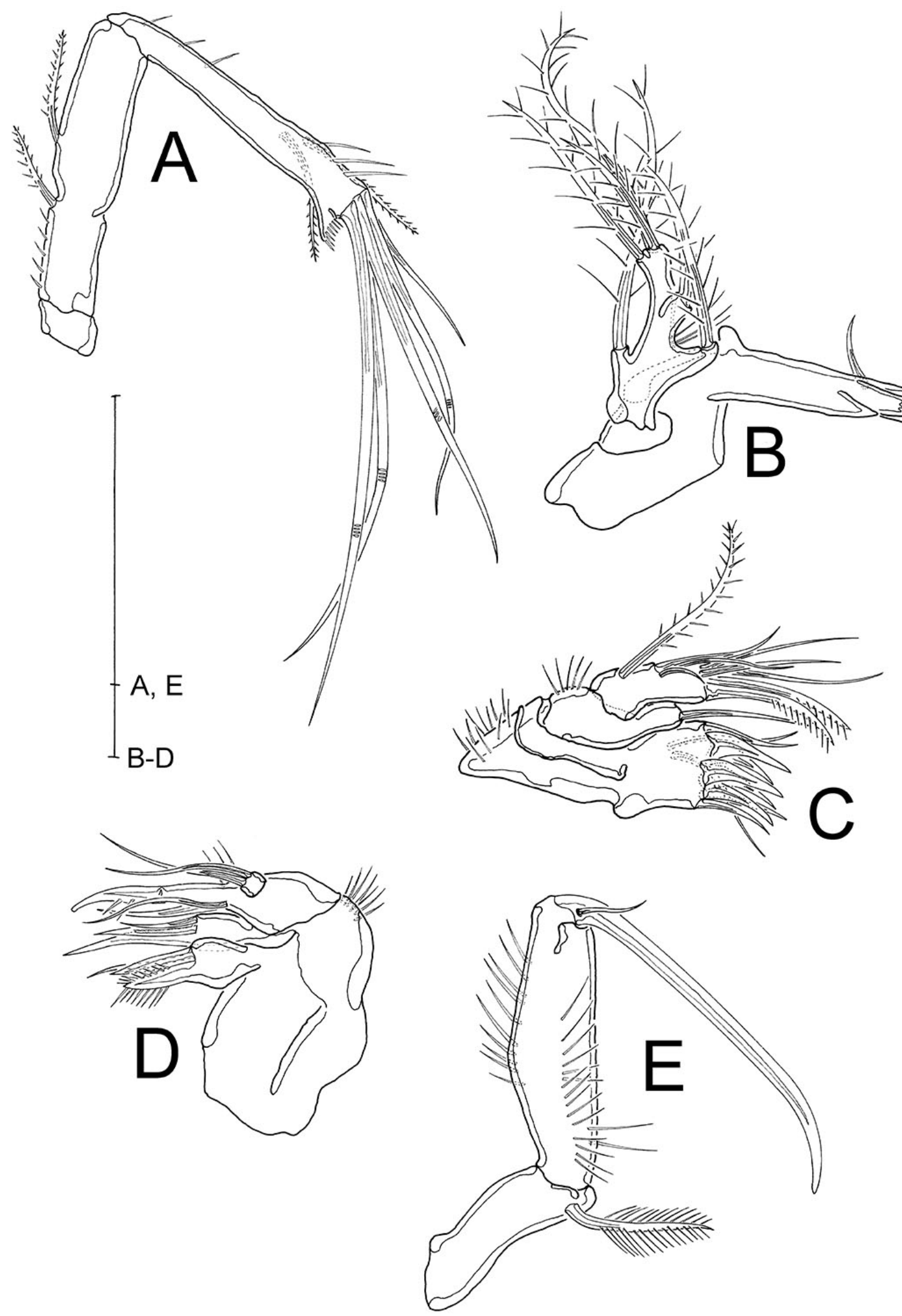

Fig. 11. Paratouphapleura aaroni gen. et sp. nov. A. Male paratype 4 (SMF 37274), A2. B-E. Female paratype 3 (SMF 37273). B. Md. C. Mxl. D. Mx. E. Mxp. Scale bars: $50 \mu \mathrm{m}$. 
thoracic somites (Fig. 8A) dorsally with 1 tube pore and paired unarmoured small cuticular processes (DP1-DP3), each carrying a sensillum at its tip; laterally with thoracic setulose tufts TST1-TST3. Following body somites without cuticular processes. P5-bearing somite dorsally with tube pore and 2 sensilla. GDS dorsally with fine suture indicating former separation; anterior part of GDS dorsally with 1 tube pore, laterally with setulose tufts (GST) accompanied by 1 tube pore; posterior part of GDS as well as subsequent abdominal somite dorsally with 2 tube pores and 2 sensilla on posterior margin, which in addition presents a row of spinules; laterally with abdominal lateral setulose tufts AST1 and AST2, each accompanied by 1 tube pore. Penultimate abdominal somite dorsally with spinulose posterior margin and with AST3 (only discernible on the right side in Fig. 8A) but without sensilla and tube pores. Telson half as long as previous somite, slightly trapezoidal, with AST4 and spinulose anal operculum flanked by 2 sensilla.

FR (Figs 8A, 9C). Diverging, rami slender, about 3.5 times as long as broad and as long as telson and preceding somite together, with 1 small tube pore proximally on outer margin and bearing 7 bare setae (Fig. 9C): setae I and II of almost the same length, inserting halfway on outer margin and set close together, I bipinnate, II bare; III bipinnate, inserting subapically on outer margin; setae IV and V located apically, IV bare, visibly smaller than III, V longest element, bipinnate; VI bare, even smaller than IV, inserting apically on inner margin; VII bare, tri-articulate, arising dorsally from small knob.

A1 (Fig. 10A). Partly or completely broken in all three females. Most complete condition present in holotype: slender, 4-segmented, first and third segments of almost the same size, about twice as long as second and fourth segment. First and second segments with several long spinules, following segments without spinulose ornamentation. First segment with biplumose seta subapically; second segment with 8 setae (5 broken); third segment with 8 setae ( 2 broken), 2 of which forming acrothek together with aes; fourth segment with 3 lateral setae; apically with at least 5 setae; acrothek that might consist of 2 additional setae and aes broken, not discernible.

Armature formula: I-1; II-8; III-6(+2+ aes), IV-8(+2? + aes?).

A2 (Fig. 11A). Without exp. Allobasis with row of spinules and 2 abexopodal bipinnate setae. Endopod laterally with few spinules, on distal half with 2 well-developed bipinnate setae, third small bare seta absent. Apically with 4 long geniculate setae and 1 smaller seta, all bare, and with spinulose frill.

MD (Fig. 11B). Gnathobase apically with 2 multicuspidate teeth; palp unilobed, with some fine, long spinules, and with 2 lateral (basal), 3 apical (endopodal), and 1 outer (exopodal) setae, all biplumose.

MxL (Fig. 11C). Praecoxal arthrite with set of spinules, apically with 6 spines and on each edge with 1 seta; additionally, with 2 surface setae; all elements bare. Coxal endite apically with 1 bare seta. Basis, endopod and exopod fused to single lobe, carrying 4 lateral setae, the proximal one bipinnate, the remaining three bare; apically with 3 bare setae and 2 unipinnate spines.

Mx (Fig. 11D). Syncoxa and allobasis separated; syncoxa apically with cluster of spinules, and with 2 endites; proximal endite with 1 strong bipinnate spine, fused to segment, and with 2 bare setae; distal endite with bare spine fused to the segment, and with 2 bare setae. Allobasis with 1 claw-like element fused to the segment; additionally, with 2 bare setae. Endopod 1-segmented, small, with 2 bare setae.

Mxp (Fig. 11E). Prehensile, syncoxa without spinules but with 1 biplumose seta on apical edge; basis with 2 rows of long spinules; endopod produced into long bare claw, basally accompanied by 1 tiny seta.

P1 (Fig. 10B). With transversely elongated basis and 2-segmented exo- and endopod. Praecoxa small, triangular; coxa small, more or less rectangular. Basis with several long spinules on anterior margin, and 


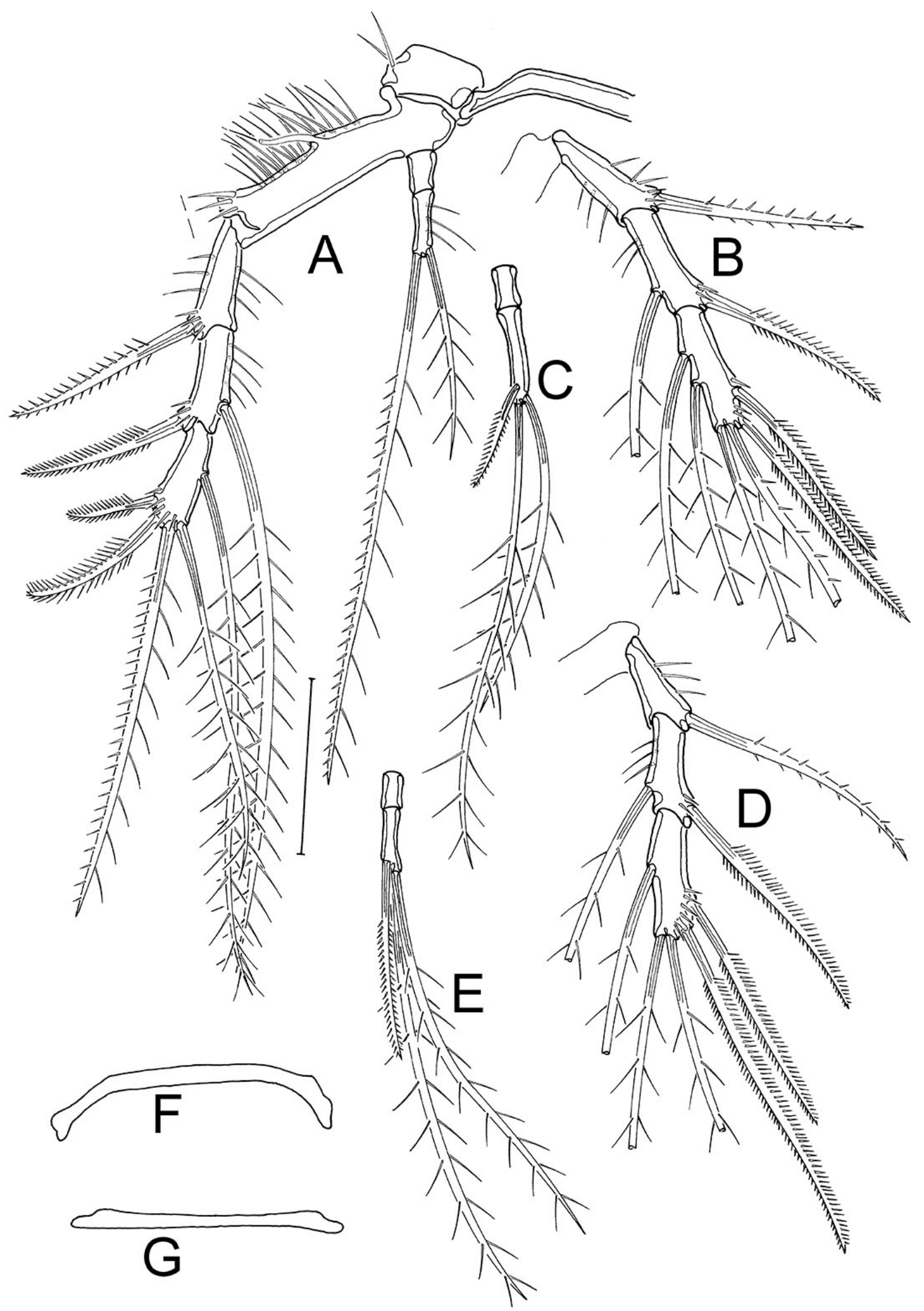

Fig. 12. Paratouphapleura aaroni gen. et sp. nov., female paratype 3 (SMF 37273). A. P2. B. P3 exopod. C. P3 endopod. D. P4 exopod. E. P4 endopod. F. P3 intercoxal sclerite. G. P4 intercoxal sclerite. Scale: $50 \mu \mathrm{m}$. 
Table 2. Paratouphapleura aaroni gen. et sp. nov., setation of swimming legs P2-P4; Roman numerals indicate outer, Arabic numerals inner elements.

\begin{tabular}{lll}
\hline Leg & Exopod & Endopod \\
\hline P2 & I- $0 ;$ I-I; II-2-1 & $0 ; 0-2-0$ \\
P3 male & I- $0 ;$ I-1; II-2-2 & $0 ; 0$ (apophysis); $0-2-0$ \\
P3 female & I- $0 ;$ I- $-1 ;$ II-2-2 & $0 ;$ I-2-0 \\
P4 female & I- $0 ;$ I-I $;$ II-2-1 & $0 ;$ I-2-0 \\
\hline
\end{tabular}

with 1 inner and 1 outer element (broken in Fig. 10B). Exopodal segments of nearly the same size, exp1 with row of spinules on outer distal margin, and with 1 outer bipinnate seta; exp-2 without spinules, with 1 bipinnate outer seta, and (sub)apically with 4 geniculate elements, all with row of pinnules previous to geniculation.

P2-P4 (Fig. 12A-G). With slender, bow-like intercoxal sclerites (P3: Fig. 12F; P4: Fig. 12G) and transversely elongated bases that carry long spinules and 1 tube pore on their anterior margins, as shown for P2 (Fig. 12A). Exp-1 with few spinules on inner and/or outer margin, posteriorly with 1 bipinnate spine; exp-2 also with few spinules as depicted, and with 1 inner biplumose seta and 1 bipinnate outer spine; exp-3 with 2 outer bipinnate elements, short and spine-like in P2 but long and seta-like in P3 and P4; additionally, with 2 apical biplumose setae; inner margin of exp-3 with 1 biplumose seta in P2 and P4, but with 2 biplumose setae in P3. Endopods small and 2-segmented, enp-1 shorter than enp-2, without ornamentation; P2 enp-2 with few spinules and 2 apical setae, outermost pinnate on the outer but plumose on the inner margin, innermost seta biplumose and not reaching half the length of the outer one; enp-2 of $\mathrm{P} 3$ and $\mathrm{P} 4$ each with 2 biplumose apical setae, and with 1 outer bipinnate seta reaching at most $1 / 3(\mathrm{P} 3)$ or half (P4) the length of the apical elements. Setation of P2-P4 as in Table 2.

P5 (Fig. 13A). Baseoendopod and exopod distinct. Baseoendopod with outer bipinnate seta arising from long slender setophore (broken in Fig. 13A) and accompanied by 1 long tube pore and long spinules. Endopodal lobe minute, with 1 long bipinnate seta on its distal part, and with 1 tube pore. Exopodal lobe slightly longer than baseoendopod, with 2 outer, 1 subapical, and 2 apical bipinnate setae; subapically with long tube pore.

GF (Fig. 9D). With single gonopore; P6 not forming genital operculum; lobes strongly reduced, each ending in a small bare seta (1 seta broken in Fig. 9D).

\section{Male}

The male (Fig. 8B) resembles the female in most characters. Sexual dimorphism consists of a slightly smaller body size (allotype: $410 \mu \mathrm{m}$, paratype 4: $417 \mu \mathrm{m}$, paratype 5: $459 \mu \mathrm{m}$ ), smaller dorsal cuticular processes DP1-DP3, the A1, the P3 endopod, the P5, and the absence of a P6.

A1 (Fig. 14A). 7-segmented, subchirocer. First segment with long spinules on surface and anterior margin, and with 1 seta apically (broken in Fig. 14A); second segment as long as first, with 8 bare setae (two of which broken in Fig. 14A); third segment small, almost triangular, with 4 bare setae; fifth segment minute, with 2 small bare setae; sixth segment swollen, setation not discernible because of 


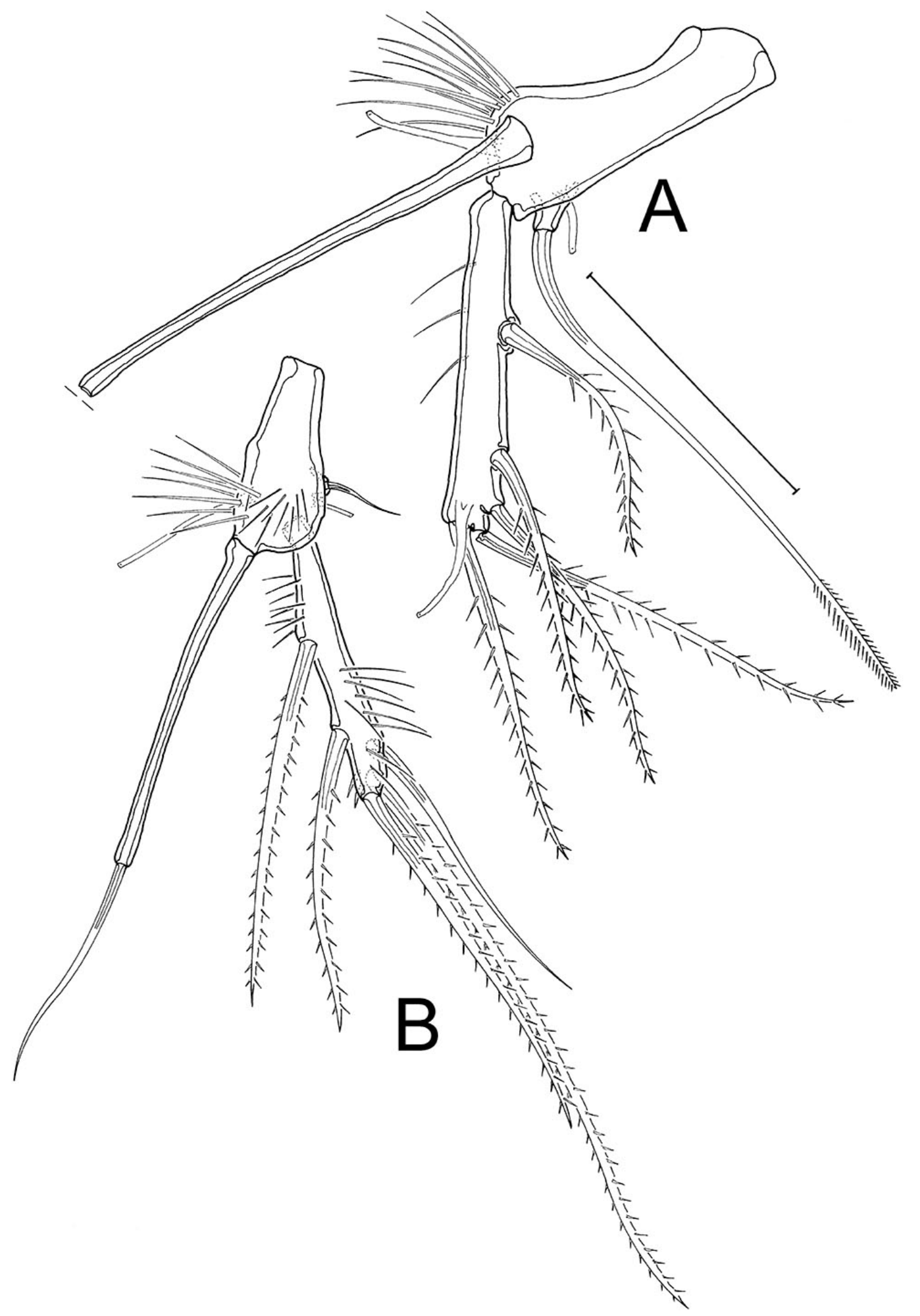

Fig. 13. Paratouphapleura aaroni gen. et sp. nov. A. Female paratype 3 (SMF 37273), P5. B. Male paratype 4 (SMF 37274), P5. Scale bar: $50 \mu \mathrm{m}$. 


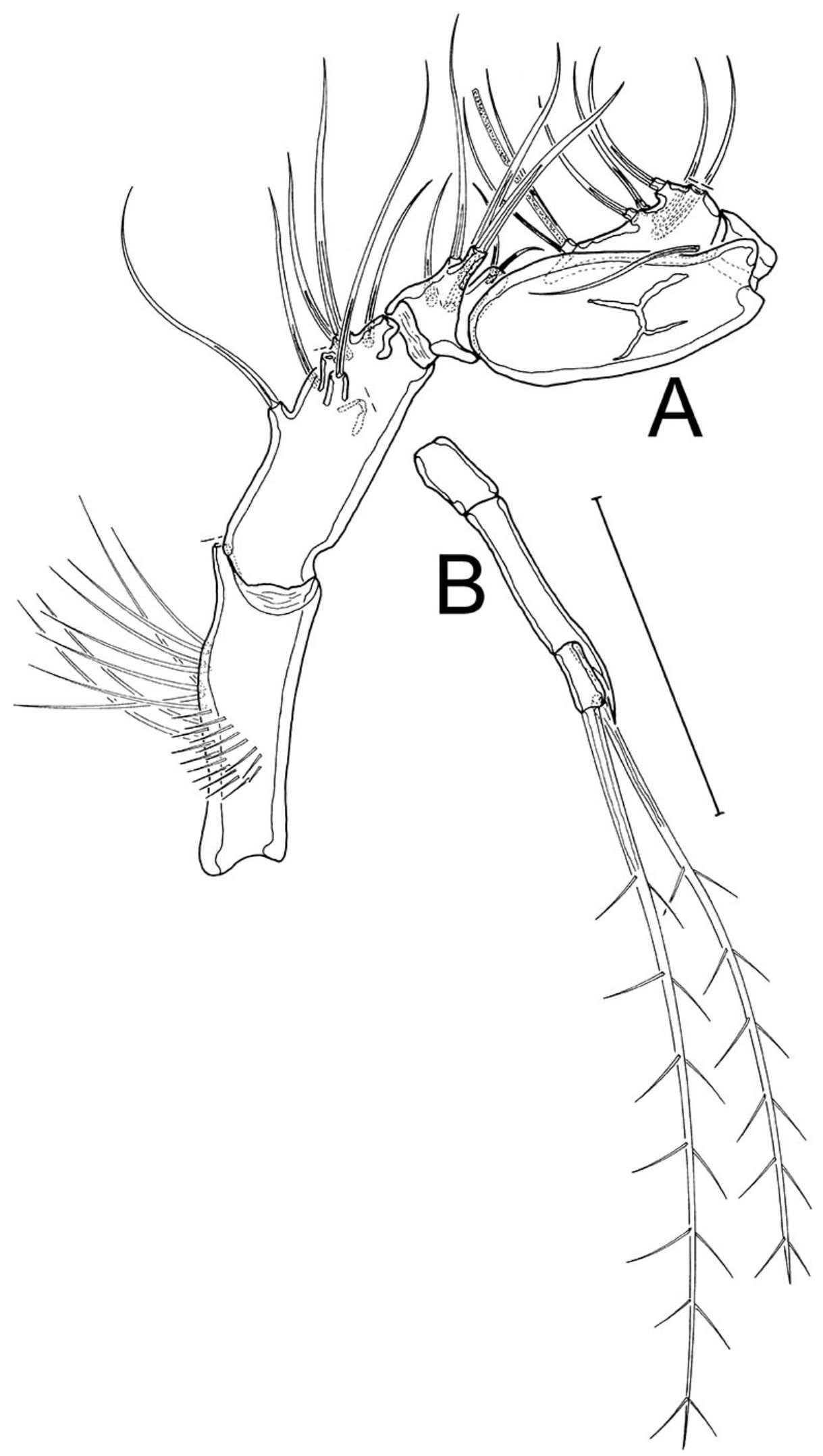

Fig. 14. Paratouphapleura aaroni gen. et sp. nov., male paratype 4 (SMF 37274). A. A1. B. P3 endopod. Scale bar: $50 \mu \mathrm{m}$. 
position on the slide and the risk of breaking the A1 if it is turned (its description is therefore postponed until additional material is found) sixth segment small and squarish, without ornamentation; seventh segment twice as long as sixth, tapering posteriorly, with 9 bare setae, 2 of which form an apical acrothek together with 1 aes.

P3 ENDOPOD (Fig. 14B). 3-segmented, first segment small and unarmed, second segment about three times as long as first, ending in acute apophysis; third segment slightly shorter and narrower than first, not reaching end of apophysis, with 2 long biplumose setae apically.

P5 (Fig. 13B). Exopod separated from baseoendopod, with several long spinules and 2 outer and 2 apical bipinnate setae; additionally, with 1 subapical bare seta but without tube pore; baseoendopod as in female but endopodal lobe smaller, likewise the single endopodal seta, which is small and bare.

Pseudopolyascophorus gen. nov.

urn:1sid:zoobank.org:act:D9585661-5A33-40AF-938F-CA881880B7E9

\section{Type and only species}

Pseudopolyascophorus monoceratus (George et al., 2013) gen. et comb. nov. Polyascophorus monoceratus George et al., 2013: 20-33, figs 2-8.

\section{Etymology}

The genus name is compound by the Greek $\psi \varepsilon v \delta \eta \dot{~[p s e u d e s] ~(' m i s l e a d i n g ', ~ ' d e c e i v i n g ') ~ a n d ~ t h e ~}$ genus name Polyascophorus, indicating an ostensible morphological similarity of Polyascophorus and Pseudopolyascophorus gen. nov. Gender: masculine.

\section{Diagnosis}

Member of Cletodidae T. Scott, 1904, Cletodinae T. Scott, 1904 and the Ceratonotus group sensu ConroyDalton (2001). Body more or less cylindrical, tapering slightly posteriorly, without clear demarcation between pro- and urosoma. Sexual dimorphism in A1, P3, P4, P5, and P6; females with GDS due to fusion of last (P6-bearing) thoracic and first abdominal (genital) somite. Cphth comprising approximately $1 / 4$ of body length; rostrum fused to cephalothorax, enlarged and Y-shaped; with long tube pore but no rostral setulose tuft (RST). Cphth with paired knobbed frontolateral horns (FLH), cephalothoracic posterior lateroventral (CLVPp) and laterodorsal processes (CLDPp); CLVPp bifurcated. Thoracic somites bearing P2-P5 with dorsal cuticular processes DP1-DP4. First abdominal somite (= posterior part of female GDS) with single centred DP5. Cphth, body somites, and furca with tube pores dorsally and/or laterally. Furcal rami barely 4 times as long as broad, rounded at their apical outer margin; with 7 setae (I-VII). Female A1 4-segmented, with first segment elongated and bearing long spinules on inner margin, and with aesthetasc on third and fourth segment. Male A1 6-segmented, subchirocer. A2 with allobasis, without endopod; allobasis with 2 abexopodal setae. Endopod as long as allobasis, with 2 spinulose frills (sub)apically. P1 with 2-segmented exopod; exp-1 with 1 bipinnate outer spine, exp2 with 4 apical, geniculate setae and 1 outer spine; endopod 2-segmented in female, with 1 apical seta, absent in male. P2-P4 with 3-segmented exopods; exp-1 with 1 outer spine, exp-2 with 1 outer spine and 1 inner seta; exp-3 with 2 outer spines and 2 apical setae, and with 1 (P2, P4) or 2 (P3) inner setae. P2 without endopod. P3 endopod in female 2-segmented, carrying 2 apical setae; in male 3-segmented with a small bare enp-1, elongated enp-2 with a curved apophysis on inner apical margin, and 2 apical setae on small enp-3. P4 endopod 2-segmented; enp-1 small, unarmed, enp-2 in female with 1 apical seta; in male with 2 apical setae and 1 outer spine. P5 with baseoendopod and exopod fused, sexually dimorphic; endopodal lobe completely reduced and represented by 1 seta and 1 tube pore in female, and by 2 setae and 2 tube pores in male. Female genital field with gonopore covered by genital operculum formed by the reduced $\mathrm{P} 6$, with 1 seta on each side. 
Tauroceratus gen. nov.

urn:1sid:zoobank.org:act:7A9A1E20-76EB-4AD2-9795-8C09DFD9854B

\section{Type species}

Tauroceratus tauroides (George, 2006) gen. et comb. nov. (by designation).

Ceratonotus tauroides George, 2006: 89-100, figs 1-9.

\section{Additional species}

Tauroceratus concavus (Conroy-Dalton, 2003) gen. et comb. nov.

Ceratonotus concavus Conroy-Dalton, 2003a: 79-82, figs 7-8.

Tauroceratus steiningeri (George, 2006) gen. et comb. nov.

Ceratonotus steiningeri George, 2006b: 99-107, figs 10-15.

Tauroceratus vareschii (George, 2006) gen. et comb. nov.

Ceratonotus vareschii George, 2006b: 107-113, figs 16-20.

\section{Etymology}

The genus name Tauroceratus is a combination of the Greek $\tau \alpha$ ópos [távros], meaning 'bull', and the

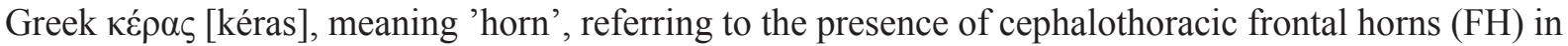
the assigned species. Gender: masculine.

\section{Diagnosis}

Member of Cletodidae T. Scott, 1904, Cletodinae T. Scott, 1904, and the Ceratonotus group sensu Conroy-Dalton (2001). Body cylindrical, tapering slightly posteriorly, without clear demarcation between pro- and urosoma. Sexual dimorphism in A1, P3, P5, and P6; females with GDS due to fusion of last (P6-bearing) thoracic and first abdominal (genital) somites. Cphth about $1 / 3$ of total body length, with some sensilla laterally and dorsally; cephalic front produced into a massive peak. Cphth frontally with pair of frontal horns (FH) that carry the rostral setae, and dentate frontolateral horns (FLH); posteriorly with dendroid cephalothoracic laterodorsal processes (CLDPp). Cephalothoracic anterior lateroventral processes (CLVPa) and cephalothoracic posterior lateroventral processes (CLVPp) developed. Rostrum absent, original position indicated by tube pore. P2-P5-bearing pedigerous somites dorsally with dendroid cuticular processes (DP1-DP4). Last pedigerous somite (= anterior half of female GDS) with sensilla on posterior margin that arise from tubercles dorsally (DT1) and small conical sensillate tubercles (LT1) laterally (not confirmed for T. tauroides gen. et comb. nov.). First abdominal somite (i.e., posterior half of female GDS) dorsally with dendroid DP5, second abdominal somite dorsally with conical DP6, and laterally with small conical lateral sensillate tubercles (LT2) (not confirmed for T. steiningeri gen. et comb. nov.). Telson broader than long, trapezoidal in dorsal view, anal operculum flanked by 2 sensilla, posterior margin bare or with row of spinules. Furcal rami long and slender, diverging, with 7 setae. Female A1 slender, 3-segmented, 5-6-segmented and (sub)chirocer in male. A2 without exopod, allobasis with 1 abexopodal seta on endopodal half. Intercoxal sclerites of P1P4 slender, bow-like; P1 with transversely elongated basis and 2-segmented exo- and endopod; exp-2 longer than exp-1, with 1 outer and 1 subapical bipinnate spine and 3 geniculated apical setae. P2-P4 with transversely elongated bases, 3-segmented exopods and 2-segmented endopods except male P3 endopod, which is 3-segmented. Exp-1 with 1 outer bipinnate spine, without inner seta; exp-2 with 1 bipinnate outer spine and 1 biplumose inner seta, exp-3 with 2 bipinnate outer spines, 2 biplumose apical and 1 (P2, P4) or 2 (P3) biplumose inner setae. Enp-1 small and bare, enp-2 elongate, with 1 biplumose apical seta in P2 and 1-2 apical elements in P3 (female) and P4; male P3 enp-1 as in female, enp-2 elongate and bearing cuspidate apophysis on inner apical margin; enp-3 nearly as small as enp-1, with 1-2 setae. P5 with distinct exopod in both sexes, baseoendopod smaller than exopod, with outer seta arising from small projection; endopodal lobe completely absorbed into basis, with 2 setae in the female and 1 seta in the male. Exopod apically with 3 bipinnate setae. 


\section{Discussion}

\section{Establishment of Poropsyllus gen. nov. and assignment of Po. menzelae gen. et sp. nov.}

The new species described here shares all autapomorphies of the Ceratonotus group listed by George (2020), but it cannot be placed in any of the known genera, as it does not share the respective generic autapomorphies. Instead, Po. menzelae gen. et sp. nov. presents a set of 13 autapomorphies [plesiomorphic states in square brackets]:

1. Cphth frontally produced into robust peak with strong concave front [peak of cphth absent or weak; front only weakly rounded];

2. Cephalothoracic anterior lateroventral extensions (CLVEa) prolonged into ventrally directed cephalothoracic anterior lateroventral processes $(\mathrm{CLVPa})$ [no prolongation of CLVEa];

3. Rostrum lost [rostrum at least minute];

4. FR seta II bare [seta at least unipinnate];

5. P1 endopod represented by 1 seta [endopod at least 1 -segmented];

6. P2 basis extremely elongated transversely, reaching length of entire thorax [P2 basis not longer than two thoracic segments];

7. P3 basis extremely elongated transversely, as long as entire thorax [P3 basis not longer than two thoracic segments];

8. $\mathrm{P} 4$ basis extremely elongated transversely, as long as entire thorax [P4 basis not longer than two thoracic segments];
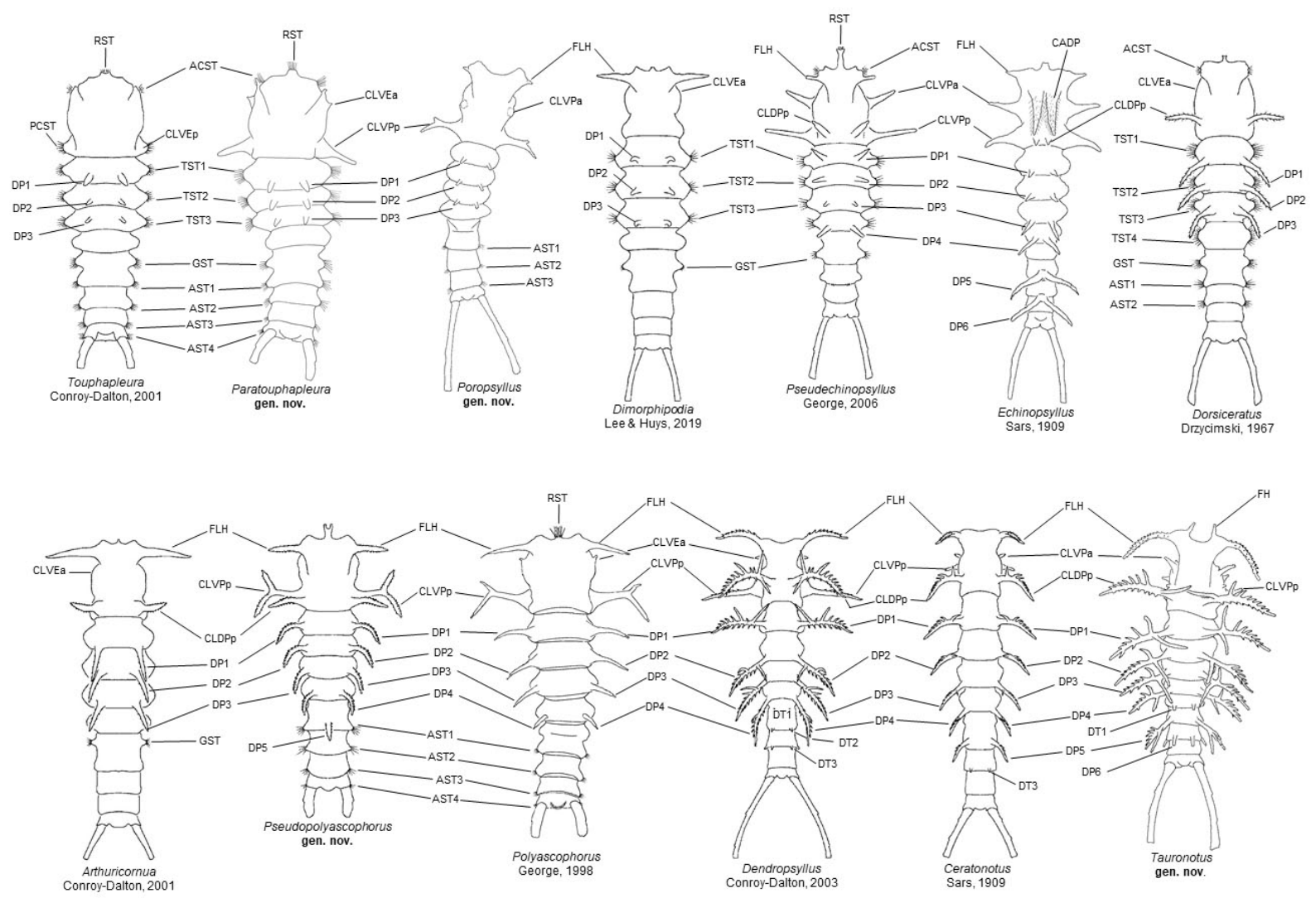

Fig. 15. Schematic illustrations of the 13 genera assigned to the Ceratonotus group, indicating the positions of the cuticular processes, socles, and setular tufts, amended from Lee \& Huys (2019). Abbreviations according to the abbreviations list in the text. 
9. Female P3 without endopod [female P3 endopod present];

10. $\mathrm{P} 4$ without endopod [P4 endopod present];

11. P5 extremely elongated, reaching anterior margin of telson [P5 reaching posterior margin of GDS only];

12. P5 seta II lost [seta II still present];

13. P5 seta 4 bare [bipinnate].

Character 1, cphth frontally produced into robust peak with strong concave front: in certain species (i.e., Touphapleura schminkei (George, 1998), Paratouphapleura aaroni gen. et sp. nov., Dorsiceratus spp., Echinopsyllus spp.) the front of the cphth is more or less straight, with the narrow, small rostrum in its centre and the departures of the antennules protruding on its anterior corners (cf. George 1998; ConroyDalton 2003b; George 2006a). In other species the cephalothoracic front became slightly concave, as a result of the complete reduction of the rostrum (Ceratonotus spp., Dendropsyllus spp.) (George \& Schminke 1998; Conroy-Dalton 2003a; George 2006b) or the increased protrusion of the antennular departures (Arthuricornua anendopodia Conroy-Dalton, 2001; Dimorphipodia changi Lee \& Huys, 2019; Polyascophorus spp.; Pseudechinopsyllus sindemarkae George, 2006; and Pseudopolyascophorus monoceratus gen. et comb. nov.) (George 1998; Conroy-Dalton 2001; George 2006a; George et al. 2013; Lee \& Huys 2019). In Tauroceratus gen. nov. this concave shape reaches its maximum because of the combination of both the above-mentioned features and the additional formation of anteriorly directed frontal horns (FH; cf. Fig. 15, and see below). Poropsyllus gen. nov. shows an intermediate condition: its rostrum has been completely lost, and the antennular departures are strongly developed, but it lacks the FH. That condition is unique within the Ceratonotus group and thus hypothesized here as autapomorphic for Poropsyllus gen. nov.

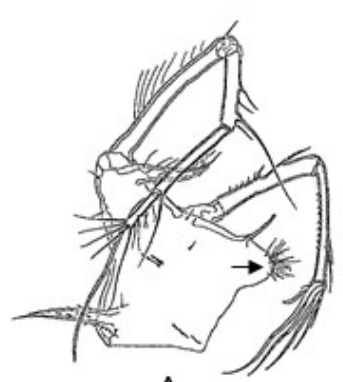

A

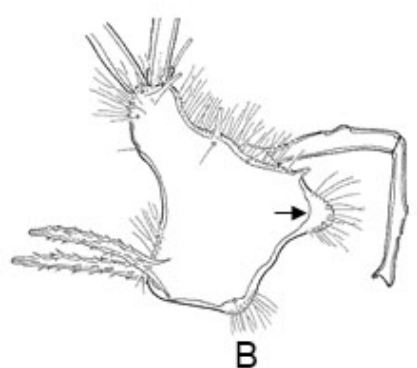

B
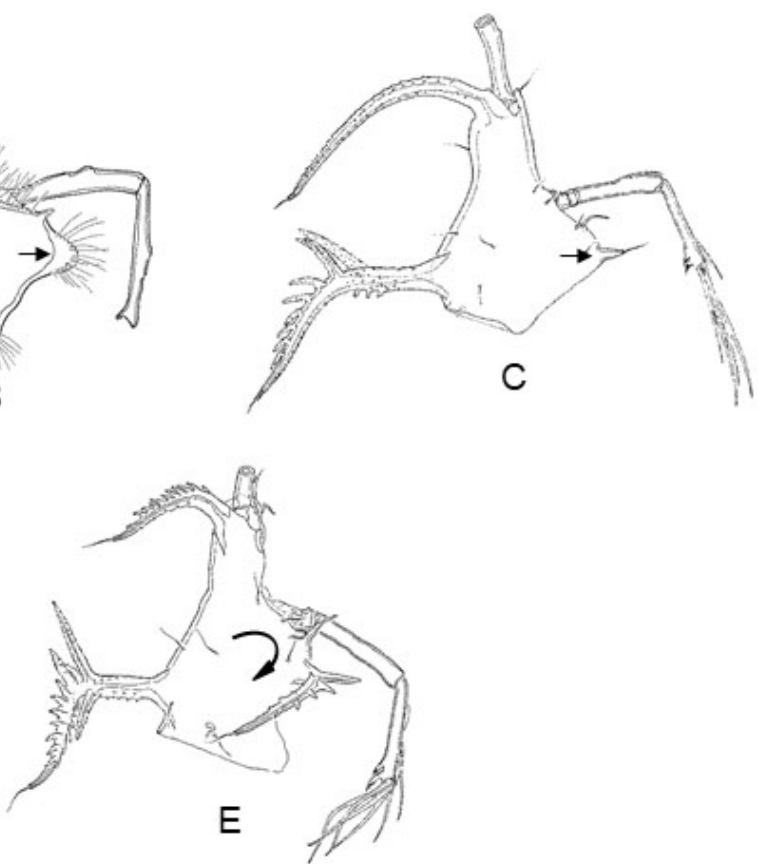

Fig. 16. Lateral view of the cphth. A. Arthuricornua anendopodia Conroy-Dalton, 2001. B. Dorsiceratus sp. (DIVA 1, \#346/8-8). C. Ceratonotus thistlei Conroy-Dalton, 2003. D. Poropsyllus menzelae gen. et sp. nov. E. Dendropsyllus thomasi Conroy-Dalton, 2003. No scales. Arrows indicate the position and direction of the CVEa (A-B) and CLVPa (C-E). A modified from Conroy-Dalton (2001); B, D originals; C, E modified from Conroy-Dalton (2003a). 

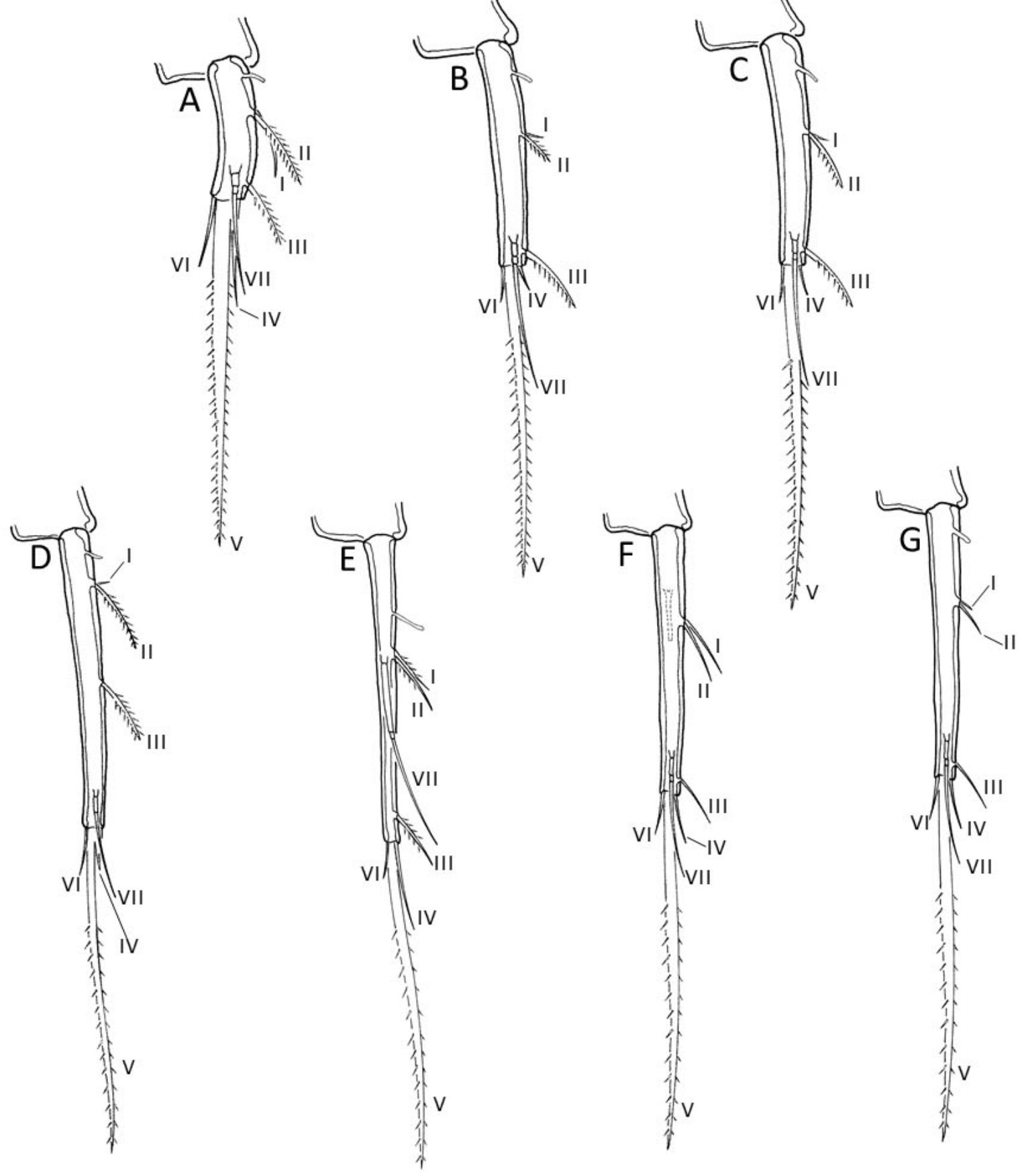

Fig. 17. Schemes of the general shape of the furcal rami in the Ceratonotus group. A. Touphapleura ConroyDalton, 2001, Paratouphapleura gen. nov., Polyascophorus George, 1998, Pseudopolyascophorus gen. nov., Dorsiceratus Drzycimski, 1967. B. Arthuricornua Conroy-Dalton, 2001. C. Dimorphipodia Lee \& Huys, 2019. D. Dendropsyllus Conroy-Dalton, 2003, Ceratonotus Sars, 1909, Tauroceratus gen. nov. E. Echinopsyllus, Sars 1909. F. Pseudechinopsyllus George, 2006. G. Poropsyllus gen. nov. Setae numbered I-VII. 
Character 2, cephalothoracic anterior lateroventral extensions (CLVEa) prolonged into ventrally directed cephalothoracic anterior lateroventral processes (CLVPa): as recognized by Conroy-Dalton (2001) and confirmed by Lee \& Huys (2019), members of the Ceratonotus group (e.g., Fig. 16A: Arthuricornua; Fig. 16B: Dorsiceratus) present a pair of cephalothoracic anterior lateroventral extensions (CLVEa) (not confirmed for Touphapleura schminkei). In certain taxa (Ceratonotus [not confirmed for Ceratonotus coineaui Soyer, 1964], Dendropsyllus, Poropsyllus gen. nov., Pseudechinopsyllus, Tauroceratus gen. nov. [part.]) the CLVEa has become further elongated, forming cephalothoracic anterior lateroventral processes (CLVPa; cf. Fig. 15), but these CLVPa are "small, conical protuberances" (Lee \& Huys 2019: 348) in Ceratonotus (Fig. 16C) but long, ventrally directed processes in Poropsyllus gen. nov. (Fig. 16D). A further deviation is observed in Dendropsyllus (Fig. 16E), Echinopsyllus, Pseudechinopsyllus, and Tauroceratus gen. nov., whose CLVPa are directed laterally (cf. Sars 1909; Conroy-Dalton 2003a, 2003b; George 2006a, 2006b). Note, however, that the homologation of the cephalothoracic cuticular extensions, protuberances, and processes is a complex procedure that demands a careful comparison of all members of the Ceratonotus group, which is beyond the scope of the present study and is the object of ongoing investigation. Meanwhile, the ventrally directed long CLVPa are interpreted as autapomorphic for Poropsyllus gen. nov.

Character 3, rostrum lost: George (2020) hypothesized the rostral diminution as autapomorphic for the Ceratonotus group. Within that taxon, a further rostral development took place, resulting in its complete absorption into the cphth. Such complete reduction is observable in Poropsyllus menzelae gen. et sp. nov. (Figs 3A, 4A) and thus considered an autapomorphy of that genus. Nonetheless, the same is present in the genera Ceratonotus, Dendropsyllus, and Tauroceratus gen. nov. (=CeDeTa). But as these taxa do not share any other apomorphy assigned to Poropsyllus gen. nov., which for its part lacks the synapomorphies uniting CeDeTa - for example, the development of dendroid body processes, a 3 -segmented female A1, and the loss of the proximal abexopodal seta on the A2 allobasis - the complete loss of the rostrum is regarded here as convergence between Poropsyllus gen. nov. and CeDeTa. That assumption is substantiated by the circumstance that the CeDeTa group shares a set of derived characters with several other genera of the Ceratonotus group, which are, however, absent in Poropsyllus gen. nov. These are (among others) (i) strongly elongated frontolateral horns (FLH), (ii) the development of cephalothoracic laterodorsal processes (CLDPp), (iii) the remarkable elongation of dorsal processes DP1-DP3, and (iv) the lateral bend of the cephalothoracic posterior lateroventral processes (CLVPa). It is therefore concluded that CeDeTa and Poropsyllus gen. nov. belong to different lineages within the Ceratonotus group.

Character 4, furcal seta II bare: most genera of the Ceratonotus group present a uni- or bipinnate seta II on the furcal rami (Fig. 17A-E). Only two taxa are characterized by a bare seta II, namely Pseudechinopsyllus (Fig. 17F) and Poropsyllus gen. nov. (Fig. 17G). As the supposed most primitive representative - Touphapleura (cf. Conroy-Dalton 2001) - bears a bipinnate seta II, which is retained in all except the above-mentioned two genera, the transformation into a bare element is considered here to be the derived state. Because Pseudechinopsyllus and Poropsyllus gen. nov. can each be characterized by clear autapomorphies (cf. George 2006), and as Pseudechinopsyllus shares several deviations with other representatives of the Ceratonotus group that are absent in Poropsyllus gen. nov. - pointing towards a comparatively basal branch-off of the latter within the Ceratonotus group - character 4 is seen here as a convergent autapomorphy for both genera.

Character 5, P1 endopod represented by 1 seta: as substantiated by George (2020), the Cletodidae are characterized by a derived non-prehensile P1, whose endopod is reduced in size, with enp-1 and enp-2 showing almost the same size. The Ceratonotus group can be characterized by more deviations, namely (i) the transverse elongation of the P1 basis, (ii) the loss of the endopodal element 3, and (iii) the transformation of the exopodal element V into a geniculated seta (cf. George 2020). Within that taxon 


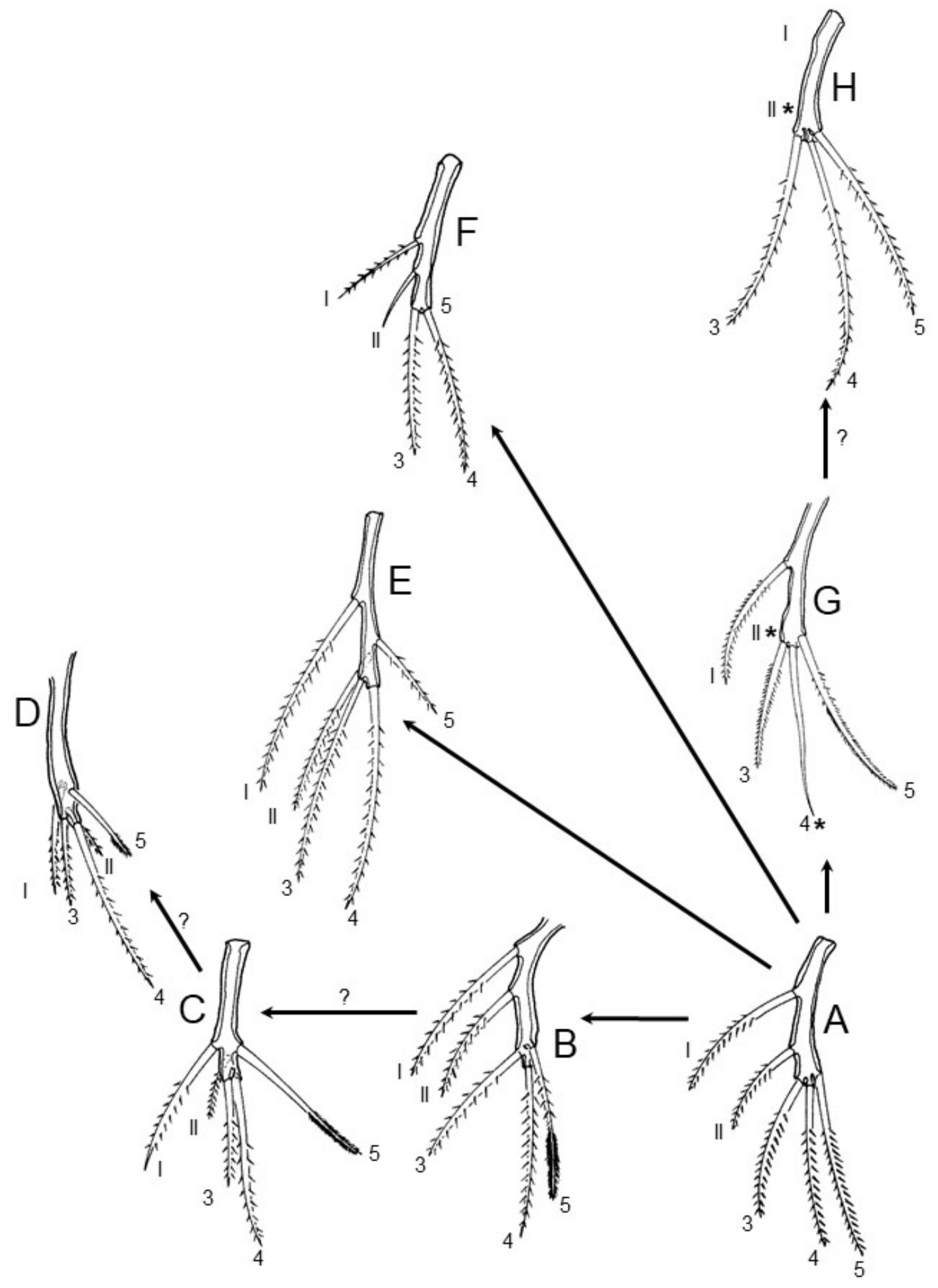

Fig. 18. Schemes of the female P5 exopod(al lobe). A. Paratouphapleura gen. nov., Pseudechinopsyllus George, 2006, Touphapleura Conroy-Dalton, 2001. B. Polyascophorus George, 1998, Pseudopolyascophorus gen. nov. C. Arthuricornua Conroy-Dalton, 2001. D. Dimorphipodia Lee \& Huys, 2019. E. Dorsiceratus Drzycimski, 1967. F. Echinopsyllus Sars, 1909. G. Poropsyllus gen. nov. H. Ceratonotus Sars, 1909, Dendropsyllus Conroy-Dalton, 2003, Tauroceratus gen. nov. Roman numerals indicate outer, Arabic numerals inner elements. Asterisks * indicate derivations referred to in the text. 
the P1 endopod underwent even further deviation. In Poropsyllus gen. nov. it is completely reduced and represented only by 1 seta. This condition is regarded as autapomorphic for that genus.

Characters 6-8, P2-P4 bases extremely elongated transversely: the extreme transverse elongation of the P2-P4 bases is particularly striking in Po. menzelae gen. et sp. nov. Although a remarkable transverse elongation of the $\mathrm{P} 2-\mathrm{P} 4$ bases is notable for all members of the Ceratonotus group and has been the object of discussion (e.g., George \& Müller 2013; George 2020), in the species described here the elongation reaches a maximum; as shown in Fig. 3A, the swimming legs stick out to surpass remarkably not only the body width but the transverse length even of the bifurcate cephalothoracic posterior lateroventral processes (CLVPp), a condition unique within the entire Ceratonotus group. This strong elongation is interpreted here as an autapomorphic character complex for Poropsyllus gen. nov.

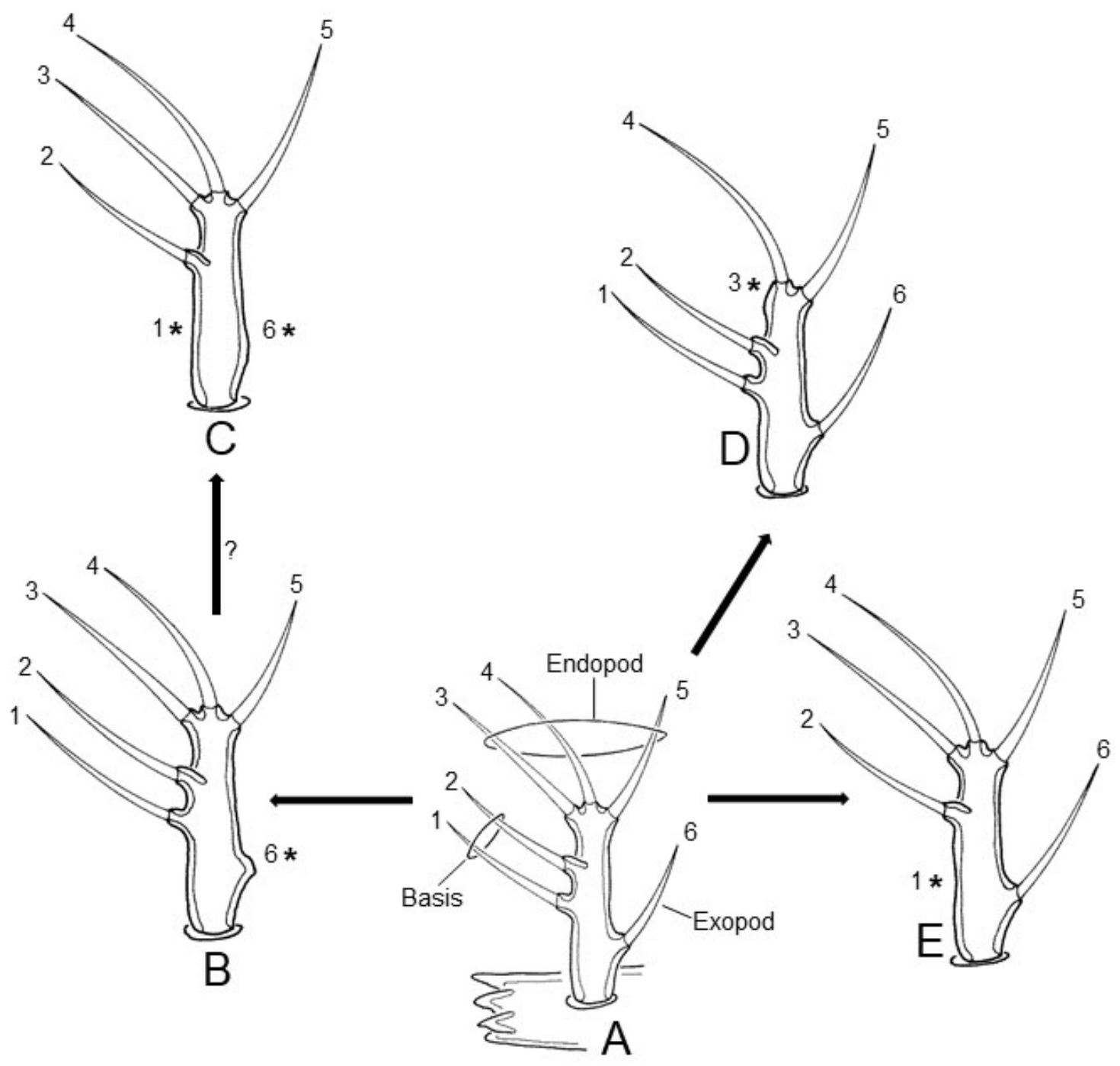

Fig. 19. Schemes of the mandibular palps. A. Paratouphapleura gen. nov. B. Arthuricornua ConroyDalton, 2001, Ceratonotus Sars, 1909, Dendropsyllus Conroy-Dalton, 2003, Polyascophorus George, 1998, Poropsyllus gen. nov., Pseudopolyascophorus gen. nov., Tauroceratus gen. nov. C. Echinopsyllus Sars, 1909, Pseudechinopsyllus George, 2006. D. Touphapleura Conroy-Dalton, 2001. E. Dimorphipodia Lee \& Huys, 2019, Dorsiceratus Drzycimski, 1967. Asterisks * indicate derived loss of setae. 
Characters 9 and 10, female P3 endopod, and P4 endopod absent: although the loss of the P2 endopod is not uncommon within the Ceratonotus group (cf. Lee \& Huys 2019: 349, tab. 2 for review), the species described here is the only one that has also lost the endopods of the P4 and the female P3. These derived characters are considered here to be autapomorphic for Poropsyllus gen. nov.

Character 11, P5 extremely elongated, reaching anterior margin of telson: the P5 of Po. menzelae gen. et sp. nov. like P2-P4 shows a remarkable elongation (Fig. 3A), reaching the length of the entire urosoma excluding the telson. Such an elongated P5 is unique within the Ceratonotus group and constitutes a clear autapomorphy of the new genus.

Characters 12 and 13, P5 seta II lost, seta 4 bare: within the Ceratonotus group, the exopod(al lobe) of the P5 presents a series of deviations, as depicted in the scheme of Fig. 18. As a homologation of the exopodal elements seems possible, and given that Touphapleura (Fig. 18A) retains the ancestral condition with 2 outer (I, II), 2 apical $(3,4)$, and 1 subapical (5) inner bipinnate elements, their modification or loss can be recognized in the other species. As shown in Fig. 18, a certain gradual development of the P5 exopod might be evident, at least in some species. For example, seta 5, which retains its original bipinnate shape in Touphapleura (Fig. 18A) and most remaining taxa (Fig. 18E-H), shows an agglomeration of finer pinnae on its distal half in Polyascophorus and Pseudopolyascophorus gen. nov. (Fig. 18B), Arthuricornua (Fig. 18C), and Dimorphipodia (Fig. 18D). Other kinds of modifications are seen in Dorsiceratus (Fig. 18E) and Echinopsyllus (Fig. 18F). Especially in the context discussed here, two deviations are of particular interest: only Poropsyllus gen. nov. (Fig. 18G) and CeDeTa (Fig. 18H) have lost the outer seta II (character 12), which is retained in all remaining taxa. As with character 3 (loss of the rostrum), the complete reduction of seta II is seen as a convergent autapomorphy for both CeDeTa and Poropsyllus gen. nov. An exclusive deviation, hypothesized here as autapomorphic, is present in the shape of seta 4 of Poropsyllus gen. nov. (character 13), which is bare (Fig. 18G), whereas all remaining members of the Ceratonotus group retain the ancestral shape of a bipinnate seta.

Autapomorphies 1-13 justify the assignment of Po. menzelae gen. et sp. nov. to a newly established genus, Poropsyllus gen. nov.

\section{Establishment of Paratouphapleura gen. nov. and assignment of Pa. aaroni gen. et sp. nov.}

A very first examination of specimens of $\mathrm{Pa}$. aaroni gen. et sp. nov. may suggest a distinctive affinity to Touphapleura, due to its quite similar shape of, e.g., the habitus; the slight dorsoventral depression of the body; the shape, size, and ornamentation with a setular tuft of the rostrum (RST); the comparatively small size of the dorsal cuticular processes DP1-DP3; the lack of cuticular processes on the urosoma; shape and size of telson and FR; and the general shape of the swimming legs. These similarities point to a potential close relationship of Touphapleura and Paratouphapleura gen. nov., which is the object of an ongoing phylogenetic study.

Nonetheless, Paratouphapleura gen. nov. presents clear autapomorphic characters when compared with Touphapleura:

14. Cephalothoracic posterior lateroventral extensions (CLVEp) extended into jet-wing-like cephalothoracic posterior lateroventral processes (CLVPp) [no (jet-wing-like) development of CLVPp];

15. Posterior cephalothoracic setulose tufts (PCST) reduced [PCST still present];

16. P3 exp-3 without tube pore [with tube pore].

Character 14, cephalothoracic posterior lateroventral extensions (CLVEp) extended into jet-winglike cephalothoracic posterior lateroventral processes (CLVPp): Touphapleura presents the posterior margin of the cphth produced into cephalothoracic posterior lateroventral extensions (CLVEp) that carry posterior cephalothoracic setulose tufts (PCST, see below, character 16) (Fig. 15). Such CLVEp are 
missing in several other genera, i.e., Arthuricornua, Dimorphipodia, and Dorsiceratus, but apparently underwent further deviation in the remaining taxa, extending into quite variable cephalothoracic posterior lateroventral processes (CLVPp) (Fig. 15). Also, Paratouphapleura aaroni gen. et sp. nov. shows strongly developed CLVPp (Figs 8A, B, 9B, 15), which are triangular and directed slightly backward, reminiscent of the wings of a jet plane. This condition is not found in any other member of the Ceratonotus group and is thus considered here to be autapomorphic for Paratouphapleura aaroni gen. et sp. nov.

Character 15, posterior cephalothoracic setulose tufts (PCST) reduced: the CLVEp in Touphapleura are armoured with apical setulose tufts (PCST). These are lost in Paratouphapleura aaroni gen. et sp. nov., which instead carries a sensillum at the tip of each CLVPp (Figs 8A, B, 9B). Apart from the PCST, Touphapleura presents setulose or spinulose tufts at the lateral margins also of the body somites (TST1-TST3, GST, AST1-AST4, cf. Fig. 15). These are also observable in Paratouphapleura aaroni gen. et sp. nov. (and in varying composition in several other genera). As such tufts are not developed in the supposed sister-group Cletodes, their development is assumed here to have taken place in the common ancestor of the Ceratonotus group, therefore forming (a derived) part of the ancestral groundpattern. Subsequently, particular tufts were reduced secondarily and independently in several species. Consequently, the loss of the PCST in Paratouphapleura aaroni gen. et sp. nov. is hypothesized here to be autapomorphic for that species and therefore for the genus Paratouphapleura gen. nov.

Character 16, P3 exp-3 without tube pore: all genera of the Ceratonotus group (including the most primitive, Touphapleura) are characterized by a tube pore borne on the subapical margin of the P3 exp- 3 . At a generic level, only two exceptions occur: Poropsyllus gen. nov. and Paratouphapleura gen. nov. The presence of this tube pore is therefore interpreted here as the ancestral condition, which could be confirmed also for Cletodes meyerorum George \& Müller, 2013. Therefore, its reduction in Poropsyllus gen. nov. and Paratouphapleura gen. nov. is seen here as the derived state. As Paratouphapleura gen. nov. seems, however, to be closely related rather to Touphapleura than to Poropsyllus gen. nov., which on its side can be characterized by a set of 13 autapomorphies (see above) missing in Paratouphapleura gen. nov., convergent reduction is assumed in both taxa.

Compared with Paratouphapleura gen. nov. (and all remaining taxa of the Ceratonotus group), Touphapleura can also be characterized by one deviation that is regarded here to be autapomorphic for that genus:

\section{Mandible palp lost seta 3 [seta 3 still present];}

As members of the Cletodoidea, all members of the Ceratonotus group bear a unilobate mandibular palpus that carries at most 6 setae (cf. George 2020: 459, tab. 1, characters 28, 29). The homologisation of the setae is possible, as their location on the palpus is quite conservative in the different species. As shown in Fig. 19A, two setae located in the direction of the gnathobase correspond to the former basis; one seta situated on the opposite side represents the exo-, and three apical setae the endopod. In the Ceratonotus group, several modifications can be observed. For instance, Paratouphapleura gen. nov. still retains the original cletodoid setation of all six setae (Fig. 19A). That condition disqualifies George's (2020) assumed apomorphic state for the Ceratonotus group - that, on the basis of the data available at that time, all members of the Ceratonotus group were characterized by a mandibular palp carrying a maximum of 5 setae only (George 2020: 460, character 76). Homologisation of these elements reveals that apart from Paratouphapleura gen. nov. all remaining species show the reduction of one or two setae (Fig. 19B, C, E); Touphapleura therefore lost the seta 3 (Fig. 19D), which is regarded as autapomorphic for that genus. 


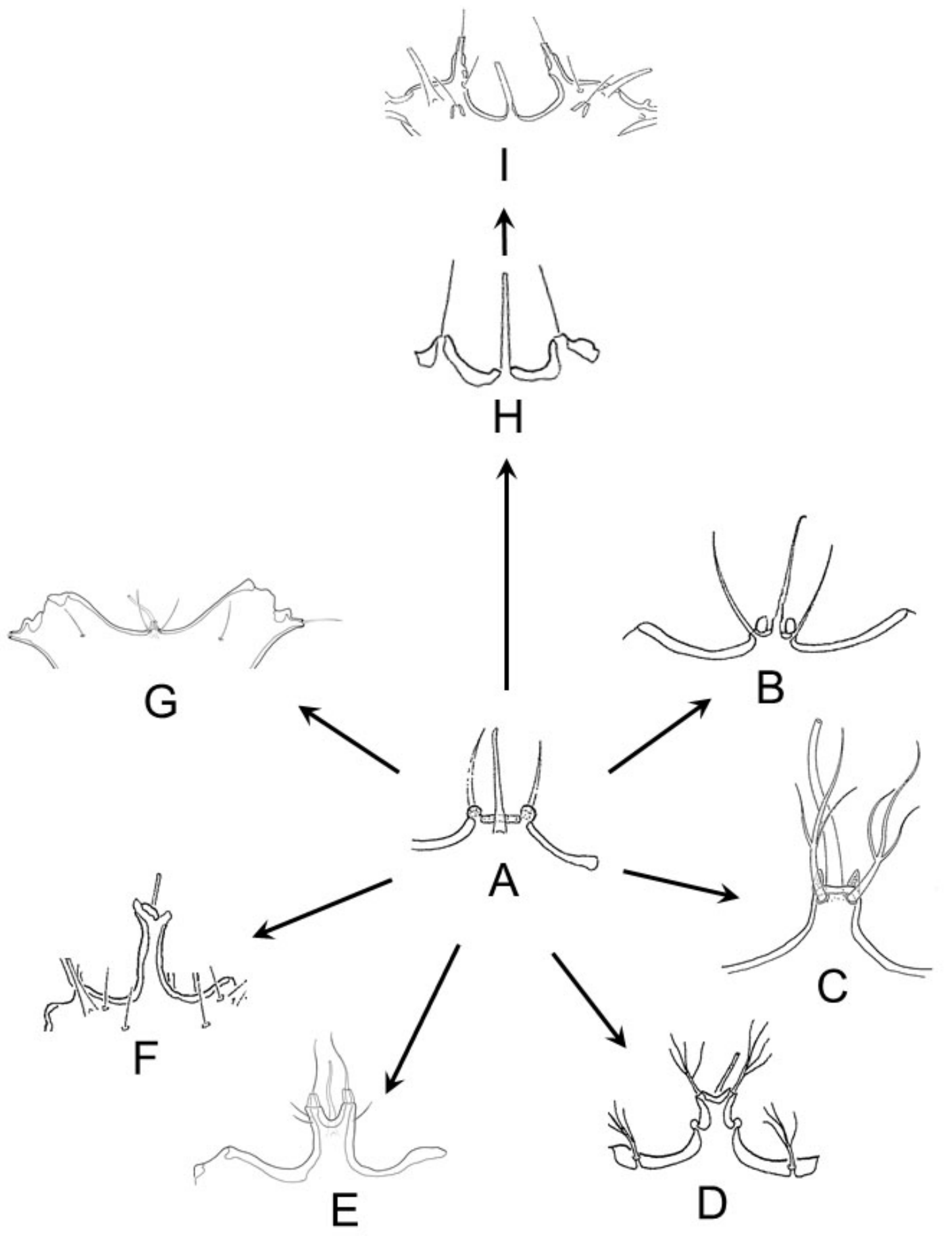

Fig. 20. Rostra. A. Touphapleura schminkei (George, 1998). B. Polyascophorus martinezi George, 1998. C. Dorsiceratus octocornis Drzycimski, 1967. D. Echinopsyllus normani Sars, 1909. E. Pseudopolyascophorus monoceratus gen. et comb. nov. F. Pseudechinopsyllus sindemarkae George, 2006. G. Poropsyllus menzelae gen. et sp. nov. H. Dendropsyllus magellanicus (George \& Schminke, 1998). I. Tauroceratus vareschii (George, 2006) gen. et comb. nov. Modified from various authors, no scales. RST in A-B and E omitted. 
Based on the supposed autapomorphies 14-16, the establishment of a new genus Paratouphapleura gen. nov. for the assignment of $P a$. aaroni gen. et sp. nov. is sufficiently justified.

\section{Establishment of Pseudopolyascophorus gen. nov. and assignment of Ps. monoceratus comb. nov.}

The systematics of and within Polyascophorus are ambiguous. To date that genus encompasses three species, namely Po. martinezi George, 1998 (type species), Po. gorbunovi (Smirnov, 1946), and Po. monoceratus George et al., 2013. When establishing the genus, George (1998) also included Polyascophorus schminkei George, 1998, which was subsequently transferred into Touphapleura by Conroy-Dalton (2001). George et al. (2013) added Po. monoceratus, justifying it by four apomorphies shared by all three species: (1) the bifurcated lateroventral posterior processes (here homologised with cephalothoracic posterior lateroventral processes (CLVPp); cf. Fig. 15) of the cphth; (2) the shorter P1 endopod, reaching at most $1 / 3$ of the length of the exopod; (3) the FR are rounded on their outer apical margin; (4) the furcal setae IV, V, and VI displaced to the inner apical edge of the FR. The further establishment of Po. monoceratus as a distinct species was supported by five exclusive deviations: (5) the development of a single cuticular process (here homologised with DP5; cf. Fig. 15) dorsally on the first abdominal somite (= anterior half of female GDS); (6) the bifurcated cephalothoracic posterior lateroventral processes (CLVPp) with the anterior branch elongated, reaching almost the length of the posterior branch; (7) the furcal seta VII biplumose in its distal half; (8) the male P1 without endopod; (9) the apical setae on the P2 exp-3 bare and geniculated. George et al. (2013) listed further deviations (the absence of cephalothoracic laterodorsal processes (CLDPp) in Po. martinezi and Po. gorbunovi, the elongated and bifurcated rostrum in Po. monoceratus, and the presence of a spinulose row dorsally on the second abdominal somite in the female of Po. monoceratus), but the authors felt unable to weight these features as plesio- or apomorphic and therefore refrained from their phylogenetic evaluation. Although neither Lee \& Huys (2019) nor George (2020) questioned the systematics within Polyascophorus, a detailed comparative re-examination of the species based on the original descriptions (Smirnov 1946; George 1998; George et al. 2013) as well as on the type material of Polyascophorus martinezi and Touphapleura schminkei revealed that the morphological differences between Po. monoceratus and the remaining two species are so grave that the retention of the former in Polyascophorus cannot be justified. Consequently, Po. monoceratus is excluded from Polyascophorus and placed in a new genus, Pseudopolyascophorus gen. nov., as Ps. monoceratus (George et al., 2013) comb. nov.

Compared with Polyascophorus, the new genus can be characterized by several autapomorphies, some of which correspond to those listed by George et al. (2013):

18. Rostrum elongated and bifurcated [rostrum minute, without bifurcation];

19. Anterior branch of cephalothoracic posterior lateroventral processes (CLVPp) elongated, almost as long as posterior branch [anterior branch markedly shorter than posterior branch];

20. Cephalothoracic laterodorsal processes (CLDPp) developed [no CLDPp developed];

21. DP5 developed [no DP5 developed];

22. Furcal seta VII biplumose on distal half [seta VII bare];

23. Maxillar endopod represented by 2 setae [mx endopod small, knob-like, with 2 setae];

24. P1 of male without endopod [male P1 with endopod];

25. P2 exp-3 apical setae bare, geniculated [apical setae biplumose, not geniculated].

Character 18, rostrum elongated and bifurcated: as shown by George (2020), the groundpattern of Cletodinae T. Scott, 1904 - encompassing the Ceratonotus group and Cletodes - consists of the ancestral state of a rostrum that is fused to the cphth and triangular with a broad base, as still observable in Cletodes. Its tip carries a pair of sensilla, and for single species (C. macrura Fiers, 1991, C. meyerorum George \& Müller, 2013) a medial tube pore as well as an apical setulose tuft are also documented (Fiers 1991; George \& Müller 2013). In the Ceratonotus group the rostrum suffered remarkable further 
modification. Its presumably most ancestral representative - Touphapleura - presents a narrow and small rostrum that is equipped with a pair of sensilla, a medial tube pore, and a rostral setulose tuft (RST) on its apical margin (Fig. 20A, cf. George 1998). This rostral shape is hypothesized here to have evolved in the last common ancestor of the species assigned to the Ceratonotus group, thus constituting an autapomorphy for it. Besides Touphapleura, that rostral shape is - turning into a plesiomorphic state within the Ceratonotus group - retained in Arthuricornua (cf. Conroy-Dalton, 2001), Dimorphipodia (cf. Lee \& Huys 2019), and Polyascophorus (Fig. 20B) (cf. Smirnov 1946; George 1998), which furthermore show a slight protrusion of the lateral edges of the cephalothoracic frontal peak.

The phylogenetic evaluation of the rostral development within the Ceratonotus group is the object of ongoing studies. Noteworthy on the topic discussed here, however, is that two evolutionary directions had apparently been pursued: (i) a rostral elongation (Dorsiceratus (Fig. 20C), Echinopsyllus (Fig. 20D) (cf. Conroy-Dalton 2003b; George 2006a; George \& Plum 2009)) that is, in some taxa (Pseudopolyascophorus gen. nov. (Fig. 20E), Pseudechinopsyllus (Fig. 20F); cf. George 2006a), combined with a bifurcation of its tip; (ii) a complete reduction of the rostrum (Poropsyllus gen. nov. (Figs 4A, 20G)), accompanied in certain taxa by the lateral displacement of the rostral sensilla toward the frontolateral margins of the cphth (Ceratonotus, Dendropsyllus (Fig. 20H); cf. George \& Schminke 1998; Conroy-Dalton 2003a; George 2006b; see also below, character 26) and the further development of frontal sensillate protrusions (Tauroceratus gen. nov. (Fig. 20I; cf. Conroy-Dalton 2003a; George 2006b). Compared with Polyascophorus, the rostral elongation and bifurcation present in Pseudopolyascophorus gen. nov. is interpreted here as autapomorphic for the latter.

Character 19, anterior branch of cephalothoracic posterior lateroventral processes (CLVPp) elongated, almost as long as posterior branch: the development of bifurcated CLVPp was assumed to support the close relation between Polyascophorus gorbunovi (Smirnov 1946), Po. martinezi, and Po. monoceratus. Indeed, the general shapes of these processes are very similar. The main difference, already noted by George et al. (2013), is the length of the anterior branch of the processes. It is much shorter than the posterior branch in both Po. gorbunovi and Po. martinezi but reaches almost the same length as the latter in Po. monoceratus. George et al. (2013), however, regarded that difference as specific. Instead, in the evaluation presented here, that deviation is considered a generic autapomorphy, because together with the remaining six derived features it underlines the outstanding phylogenetic position of $P o$. monoceratus, which allows its displacement into a new genus, Pseudopolyascophorus gen. nov., as Ps. monoceratus comb. nov.

Character 20, cephalothoracic laterodorsal processes (CLDPp) developed: George et al. (2013) rejected the assumption of Conroy-Dalton (2001), that the bifurcated cephalothoracic posterior lateroventral processes (CLVPp) of Polyascophorus gorbunovi and Po. martinezi, which both lack CLDPp, had migrated from an original laterodorsal to their lateroventral position. That rejection was substantiated by the presence of both CLVPp and CLDPp in Pseudopolyascophorus monoceratus comb. nov. The development of the latter is hypothesized here as autapomorphic for Ps. monoceratus comb. nov. in comparison with Polyascophorus.

Character 21, DP5 developed: the development of a single dorsal process on the first abdominal somite (= posterior half of the female GDS) in Ps. monoceratus comb. nov. is unique within the Ceratonotus group. It has, however, been regarded as a specific apomorphy by George et al. (2013) and was ignored in the discussion of body processes by Lee \& Huys (2019). Nevertheless, that deviation is in fact a peculiar character of Ps. monoceratus comb. nov. and is thus seen here as a clear autapomorphy of Pseudopolyascophorus gen. nov. 
Character 22, furcal seta VII biplumose at distal half: as for character 21, the development of a biplumose furcal seta VII in Ps. monoceratus comb. nov. (George et al. 2013: 23, fig. 2a, c) is unique within the whole Ceratonotus group, whose remaining members present a bare seta VII. The derived biplumose seta is therefore considered here as autapomorphic for the new genus.

Character 23, maxillar endopod represented by 2 setae: in the Cletodoidea, the maxilla is characterized by a 1-segmented endopod that bears 2 setae (George 2020: 459: character 31). That condition is still retained in most species of the Ceratonotus group; at the genus level, only Touphapleura and Pseudopolyascophorus gen. nov. show a further deviation, namely the complete loss of the maxillar endopod and its representation by 2 setae only. Whether that deviation constitutes a synapomorphy of Touphapleura and Pseudopolyascophorus gen. nov., indicating their closer phylogenetic relationship inside the Ceratonotus group, is the object of ongoing investigation.

Character 24, P1 of male without endopod: within the Ceratonotus group, the loss of the P1 endopod, which is no longer represented by even 1 seta, is reported from several taxa (Arthuricornua, Dimorphipodia, Echinopsyllus, Pseudechinopsyllus) (Conroy-Dalton 2001; Conroy-Dalton 2003b; George 2006a; Lee \& Huys 2019). In Ps. monoceratus gen. et comb. nov. this complete reduction took place in the male only, whereas in Poropsyllus gen. nov. the P1 endopod is represented by 1 seta (Fig. 5B); the remaining species (including Polyascophorus) still retain an at least a 1-segmented endopod. Thus, the loss of the P1 endopod exclusively in the male, which points towards a sexual dimorphism in Ps. monoceratus gen. et comb. nov., is seen as autapomorphic for that taxon. Whether the simultaneous loss of the P1 endopod may constitute a synapomorphy of the above-named taxa is object of an ongoing phylogenetic study.

Character 25, P2 exp-3 apical setae bare, geniculated: as for characters 21 and 22, the transformation of the apical setae in the P2 exp-3 from bipinnate/biplumose to bare but geniculated elements is a deviation that is exclusively present in Ps. monoceratus gen. et comb. nov. It is hypothesized here to be autapomorphic for Pseudopolyascophorus gen. nov.

The quality and exclusive combination of characters 18-25 justify the translocation of Polyascophorus monoceratus into a new genus.

Establishment of Tauroceratus gen. nov. and assignment of T. concavus comb. nov., T. steiningeri comb. nov., T. tauroides comb. nov., and T. vareschii comb. nov.

The most peculiar characteristics of Ceratonotus pectinatus Sars, 1909, the first species that was described for that genus (Sars 1909), are the complete lack of a rostrum on the frontal margin and the presence of cuticular processes on cphth and body somites, described as 'comb-like' by Sars (1909) but later named 'dendroid processes' by Conroy-Dalton (2001, 2003a) and following authors. Currently, the genus Ceratonotus Sars, 1909 encompasses 8 species (cf. George 2020); its closest relative is presumably Dendropsyllus Conroy-Dalton, 2003, which was established by Conroy-Dalton (2003a) to accommodate 2 species described by George \& Schminke (1998) from the southern hemisphere. By now, Dendropsyllus encompasses 5 species (George 2020).

The main difference between these two genera is the presence of dendroid processes also on the first abdominal somite (= posterior half on the female GDS) in Ceratonotus (= DP5), whereas in Dendropsyllus these processes are developed as conical tubercles (= DT2) only (Conroy-Dalton 2003a; George 2006b). Moreover, Dendropsyllus is characterized by the loss of the P2 endopod, which is still present in most Ceratonotus species, with the exception of $C$. steiningeri George, 2006, which just like the Dendropsyllus species lost the P2 endopod (cf. Conroy-Dalton 2003a; George 2006b). 
Meanwhile, the number of species in Ceratonotus increased by the description of $C$. concavus ConroyDalton, 2003, C. elongatus Gómez \& Díaz, 2017, C. steiningeri, C. tauroides George, 2006, C. thistlei Conroy-Dalton, 2003, and C. vareschii George, 2006 (Conroy-Dalton 2003a; George 2006b; Gómez \& Díaz 2017). Although all these species share the derived development of dendroid processes on the first abdominal somite, a detailed comparison revealed further deviations in certain species:

26. Development of frontal horns (FH) anteriorly on the cphth [no FH developed];

27. Transformation of DT3 into DP6 [no transformation of DT3].

Character 26, development of frontal horns (FH) anteriorly on the cphth: four Ceratonotus species, namely $C$. concavus, $C$. steiningeri, $C$. tauroides, and $C$. vareschii, present a further deviation of the cephalothoracic front. Besides the complete loss of the rostrum, which is accompanied by a lateral displacement of the rostral sensilla and a slight protrusion of the apical edges of the cphth, resulting in a somewhat concave shape of the cephalothoracic front (Fig. 20H), the four species developed conical protrusions that bear the rostral sensilla (Fig. 20I). These protrusions are named here 'frontal horns' (FH) (cf. Fig. 15); they strengthen the concave shape of the cephalothoracic front and are absent in C. coineaui, C. elongatus, C. pectinatus, and C. thistlei. Their development in C. concavus, C. steiningeri, C. tauroides, and C. vareschii constitutes a clear synapomorphy for these species.

Character 27, transformation of DT3 into DP6: according to Lee \& Huys (2019: 346, fig. 9) both Ceratonotus and Dendropsyllus are characterized by the presence of paired dorsal tubercles on the last thoracic and the first two abdominal somites (i.e., DT1-DT3; Fig. 15). These DT3 became further developed to longer conical processes (here named DP6) in the species C. concavus, C. steiningeri, C. tauroides, and C. vareschii (cf. Conroy-Dalton 2003a; George 2006b). This elongation of the former small tubercles into longer conical processes is regarded as an apomorphic character and considered as a synapomorphy of the four species. Note, however, that Ceratonotus elongatus (name!) also presents well-developed DP6 (Gómez \& Díaz 2017). That circumstance might weaken the phylogenetic quality of character 27; actually, it resembles the derived loss of the P2 endopod, which was regarded as autapomorphic for Dendropsyllus by Conroy-Dalton (2003a) but subsequently also found in Ceratonotus steiningeri (George 2006b). Otherwise, both features may be exemplary for the convergent evolution of characters; the reduction of segments as in the P2 endopod occurs quite often within the Ceratonotus group, clearly indicating the convergent character of that event and supporting the assumption that the loss of the P2 endopod happened convergently also in C. steiningeri. Similarly, the convergent development of DP6 in C. elongatus might not to be too speculative; Echinopsyllus Sars, 1909, a quite different member of the Ceratonotus group, also bears DP6 (Fig. 15; cf. Conroy-Dalton 2003b; Wandeness et al. 2009), which evolved without doubt to the most elaborated shape besides the dendroid processes of Ceratonotus/Dendropsyllus. The assumption here is therefore that the development of conical DP6 in C. elongatus is also the result of convergence.

In summary, $C$. concavus, $C$. steiningeri, $C$. tauroides, and $C$. vareschii are concluded to share the synapomorphic characters 26 and 27, with character 26 as the strongest support for their monophyletic status. Their exclusion from Ceratonotus and assignment to a new genus, Tauroceratus gen. nov., as T. concavus (Conroy-Dalton, 2003) comb. nov., T. steiningeri (George, 2006) comb. nov., T. tauroides (George, 2006) comb. nov., and T. vareschii (George, 2006) comb. nov. is therefore sufficiently justified. 


\section{Acknowledgments}

I am indebted to Dr Lena Menzel (Bremerhaven, Germany) for passing the material of Poropsyllus menzelae gen. et sp. nov. on to me for further examination. Prof. Ariel Chipman (Jerusalem, Israel) kindly left the material at my disposal and permitted the description of the new species. I wish to thank the topical editor of the EJT and two reviewers for their helpful and constructive criticism on the manuscript. I am very thankful to Dr Anne Thistle (Tallahassee, Florida, U.S.A.) for the extensive revision and correction of the English text.

\section{References}

Ax P. 1984. Das phylogenetische System. Gustav Fischer Verlag, Stuttgart.

Conroy-Dalton S. 2001. Systematics and phylogeny of the Ancorabolidae (Copepoda: Harpacticoida). II. Polyphyly of Polyascophorus and description of Arthuricornua, new genus. Journal of Crustacean Biology 21 (1): 170-191. https://doi.org/ffbtg2

Conroy-Dalton S. 2003a. Systematics and phylogeny of the Ancorabolidae (Copepoda: Harpacticoida). III. Description of two new species of Ceratonotus Sars and Dendropsyllus, new genus. Journal of Crustacean Biology 23 (1): 69-93. https://doi.org/cmdwvf

Conroy-Dalton S. 2003b. Systematics and phylogeny of the Ancorabolidae (Copepoda: Harpacticoida). IV. Redescription, ontogeny and position of Echinopsyllus normani. Cahiers de Biologie Marine 44 (2): 153-169. https://doi.org/10.21411/CBM.A.DE07F430

Drzycimski I. 1967. Zwei neue Harpacticoida (Copepoda) aus dem westnorwegischen Küstengebiet. Sarsia 30: 77-81.

Fiers F. 1991. Three new harpacticoid copepods from the Santa Maria Basin off the Californian Pacific coast (Copepoda, Harpacticoida). Beaufortia 42 (2): 13-47.

Fütterer D.K., Brandt A. \& Poore G.C.B. (eds.). 2003. The expeditions ANTARKTIS-XIX/3-4 of the Research Vessel POLARSTERN in 2002 (ANDEEP I and II: Antarctic benthic deep-sea biodiversity colonization history and recent community patterns). Berichte zur Polar- und Meeresforschung 470: $1-174$.

George K.H. 1998. Polyascophorus, a new genus of Ancorabolidae (Crustacea, Copepoda), including the description of two new species and the re-allocation of Ceratonotus gorbunovi. Vie et Milieu 48 (3): $141-155$.

George K.H. 2006a. New Ancorabolinae Sars, 1909 (Copepoda: Harpacticoida: Ancorabolidae) of the Atlantic Ocean. Description of Pseudechinopsyllus sindemarkae gen. et sp. nov. and Dorsiceratus ursulae sp. nov. from the Great Meteor Seamount, and redescription of D. octocornis Drzycimski, 1967, and D. triarticulatus Coull, 1973 (part.). Meiofauna Marina 15: 123-156.

George K.H. 2006b. New Ancorabolinae Sars, 1909 (Copepoda: Harpacticoida: Ancorabolidae) of the Atlantic and the Pacific Ocean. The taxa Ceratonotus Sars, and Dendropsyllus Conroy-Dalton. Meiofauna Marina 15: 87-122.

George K.H. 2020. Restructuring the Ancorabolidae Sars (Copepoda, Harpacticoida) and Cletodidae T. Scott, with a new phylogenetic hypothesis regarding the relationships of the Laophontoidea T. Scott, Ancorabolidae and Cletodidae. Zoosystematics and Evolution 96 (2): 455-498.

https://doi.org/10.3897/zse.96.51349

George K.H. \& Müller F. 2013. Characterization of a monophylum Echinocletodes, its exclusion from Ancorabolinae (Copepoda, Harpacticoida), and displacement of E. bodini and E. walvisi to Cletodes, including the description of two new species. Zootaxa 3666 (2): 101-136.

https://doi.org/10.11646/zootaxa.3666.2.1 
George K.H. \& Plum C. 2009. Description of two new species of Dorsiceratus Drzycimski, 1967 (Copepoda: Harpacticoida: Ancorabolidae) from Sedlo and Seine Seamounts (Northeastern Atlantic) and remarks on the phylogenetic status of the genus. Zootaxa 2096 (1): 257-286.

https://doi.org/10.11646/zootaxa.2096.1.15

George K.H. \& Schminke H.K. 1998. First records of the genus Ceratonotus G. O. Sars, 1909 (Copepoda, Ancorabolidae) from the Southern Hemisphere, with the description of two new species. Crustaceana 71: $801-817$.

George K.H., Wandeness A.P. \& Santos P.J.P. 2013. A new species of Ancorabolidae (Crustacea: Copepoda: Harpacticoida) from the Campos Basin, Brazil, including a phylogenetic review of the taxon Polyascophorus George, 1998, and a key to its species. Zoologischer Anzeiger 252: 20-33.

https://doi.org/10.1016/j.jcz.2012.02.002

Gómez S. \& Díaz K. 2017. On some new species of Ancorabolidae Sars, 1909 from the Gulf of California: the genera Ceratonotus Sars, 1909, and Dendropsyllus Conroy-Dalton, 2003 (Crustacea, Copepoda, Harpacticoida). ZooKeys 657: 43-65. https://doi.org/10.3897/zookeys.657.10725

Gooday A.J., Holzmann M., Guiard J., Cornelius N. \& Pawlowski J. 2004. A new monothalamous foraminiferan from 1000 to $6300 \mathrm{~m}$ water depth in the Weddell Sea: morphological and molecular characterisation. Deep-Sea Research II 51: 1603-1616. https://doi.org/10.1016/j.dsr2.2004.06.025

Huys R. \& Boxshall G.A. 1991. Copepod Evolution. The Ray Society, London.

Lang K. 1948. Monographie der Harpacticiden. Otto Koeltz Science Publishers, Königstein.

Lee J. \& Huys R. 2019. New Ancorabolidae (Copepoda: Harpacticoida) from Korea: two new genera, revisionary notes and updated identification keys. Zoological Journal of the Linnean Society 187: 331-377. https://doi.org/10.1093/zoolinnean/zlz019

Ockelmann K.W. 1964. An improved detritus sledge for collecting meiobenthos. Ophelia 1 (2): 217-222.

Por F.D. 1986. A re-evaluation of the family Cletodidae Sars, Lang (Copepoda, Harpacticoida). Syllogeus 58: $420-425$.

Por F.D., Steinitz H., Ferber I. \& Aron W. 1972. The biota of the Red Sea and the eastern Mediterranean (1967-1972). A survey of the marine life of Israel and surroundings. Israel Journal of Zoology 21: 459-523.

Sars G.O. 1909. Copepoda Harpacticoida. Parts 27 and 28. Cletodidae (concluded), Anchorabolidae, Cylindropsyllidae, Tachidiidae (part.). An Account of the Crustacea of Norway with Short Descriptions and Figures of all the Species 5: 305-336.

Schminke H.K. 1976. The ubiquitous telson and the deceptive furca. Crustaceana 30 (3): 292-299.

Smirnov S.S. 1946. New species of Copepoda Harpacticoida from the Arctic Ocean. Trudy Dreifuyuschei Ekspeditsii Glavsevmorputi na Ledokol'nom Parakhode 'G. Sedov' 1937-1940 3: 231-263. [In Russian, with English summary.]

Wandeness A.P., George K.H. \& Santos P.J.P. 2009. First record of the taxon Echinopsyllus (Copepoda, Harpacticoida, Ancorabolidae) from the deep sea of Campos Basin, Brazil, with the description of three new species and their contribution to phylogenetic analysis. Zoological Journal of the Linnean Society 156: 52-78. https://doi.org/10.1111/j.1096-3642.2008.00479.x 
Manuscript received: 13 April 2021

Manuscript accepted:24 June 2021

Published on: 5 October 2021

Topic editor: Rudy Jocqué

Section editor: Rudy Jocqué

Desk editor: Louise Vanson

Printed versions of all papers are also deposited in the libraries of the institutes that are members of the EJT consortium: Muséum national d'histoire naturelle, Paris, France; Meise Botanic Garden, Belgium; Royal Museum for Central Africa, Tervuren, Belgium; Royal Belgian Institute of Natural Sciences, Brussels, Belgium; Natural History Museum of Denmark, Copenhagen, Denmark; Naturalis Biodiversity Center, Leiden, the Netherlands; Museo Nacional de Ciencias Naturales-CSIC, Madrid, Spain; Real Jardín Botánico de Madrid CSIC, Spain; Zoological Research Museum Alexander Koenig, Bonn, Germany; National Museum, Prague, Czech Republic. 